\title{
SAÚDE E EDUCAÇÃO: INVESTIMENTOS E EFETIVIDADE MUNICIPAL
}

HEALTH AND EDUCATION: INVESTMENT AND MUNICIPAL EFFECTIVENESS

Recebido em 10.12.2019 Aprovado em 06.03.2020

Avaliado pelo sistema double blind revien

DOI: https://doi.org/10.12712/rpca.v14i2.39827

\section{Mayte Cardoso Aguiar}

mayteaguiar@hotmail.com

Fucape Business School - Vitória/ES, Brasil

https://orcid.org/0000-0003-3528-6910

\section{Aridelmo Teixeira}

aridelmo@fucape.br

Fucape Business School - Vitória/ES, Brasil

https://orcid.org/0000-0002-4909-1025

\section{Aziz Beiruth}

aziz@fucape.br

Fucape Business School - Vitória/ES, Brasil

https://orcid.org/0000-0001-6962-3044

\section{Resumo}

Objetiva-se avaliar se os investimentos em saúde e educação realizados pelos municípios do Estado do Espírito Santo têm impactado no Índice de Efetividade de Gestão Municipal - IEGM. Os resultados evidenciaram que os investimentos na saúde somente geram impactos positivos na efetividade no exercício posterior, e que na educação, os impactos na efetividade não são percebidos. Os resultados permitem inferir ser a gestão do investimento que traduz efetividade. Conclui-se que a decisão na alocação dos recursos deve se pautar em critérios técnicos, e que o controle externo deve considerar a adoção de indicadores que impactam a qualidade de vida da sociedade.

Palavras-chave: Investimentos em educação e saúde. IEGM. Efetividade. Controle. Tribunais de Contas.

\begin{abstract}
The objective consists of evaluating if investments in health and education made by the municipalities of the state of Espirito Santo have impacted the Municipal Management Effectiveness Index - IEGM. Results showed that investments in health field only generate positive impacts on effectiveness in the subsequent period, and in education field, impacts are not perceived. Findings allow inferring that is management that translates investment into effectiveness. It is concluded that the decisions on resource allocation should be based on technical criteria, and that external control should consider the adoption of indicators that impact the quality of life of society.
\end{abstract}

Keywords: Investments in health and education. IEGM. Effectiveness. Control. Courts of Accounts. 


\section{Introdução}

Com a promulgação da Constituição Federal de 1988, foram estabelecidas novas competências e responsabilidades aos entes da Federação, especialmente para os municípios, que passaram a ser responsáveis por sua própria arrecadação, pelo recebimento de transferências dos estados e da União, bem como, pela gestão e investimento desses valores (Constituição do Brasil,1988). Deste modo, verificou-se um aumento de recursos públicos disponíveis nos caixas dos municípios para que fizessem a gestão e a devida oferta de serviços públicos à população (Caetano, Ávila \& Tavares, 2017).

Nesse ínterim, tendo em vista o quantitativo de recursos a cargo da administração municipal, o Poder Legislativo, por meio de Emendas Constitucionais (especialmente as Emendas Constitucionais 29 e 86) e de Leis Complementares (como a LC 101), entendeu por estabelecer que o percentual de destinação mínima dos recursos sobre a receita líquida dos municípios seria de $25 \%$ para educação e de 15\% para saúde (Silva, Ferreira, Braga, \& Abrantes, 2012), cabendo, aos Tribunais de Contas fiscalizar seu cumprimento.

Todavia, o investimento aplicado pelos municípios tem interferido de maneira positiva em seus indicadores de efetividade de saúde ou educação?

Ante esse questionamento, partindo da hipótese de que quanto maior o investimento em saúde e educação, melhores os índices de efetividade, o presente estudo objetivou averiguar o impacto do investimento per capita em saúde e o investimento por aluno em educação, no Índice de Efetividade da Gestão Municipal - IEGM, no período de 2015 a 2017, abrangendo em sua amostra de pesquisa todos os municípios do Estado do Espírito Santo.

Ressalta-se que o IEGM: Índice de Efetividade de Gestão Municipal é um indicador adotado pelos Tribunais de Contas de todo o país e se dedica a mensurar a eficácia das políticas públicas municipais sob 7 dimensões: saúde, educação, meio ambiente, planejamento, gestão fiscal, governança em TI e cidades protegidas (IRB- Instituto Rui Barbosa).

Quando o tema tangência a relação entre investimento, efetividade e gestão, pesquisas apontam que a administração pública tem passado por processos de reforma inspirados em modelos organizacionais (Parsons, 2006), e nestas reformas, a administração pública, que outrora se identificava com um modelo burocrático, hoje reflete, em seus processos e desenho estrutural, características voltadas à administração pública gerencial e à governança publica (Secchi, 2009).

Dentro dessa nova perspectiva da administração pública orientada à governança, temos a atuação dos gestores nem sempre dirigida à entrega de resultados que de fato impactem positivamente na vida do cidadão, ou seja, a ações que devem traduzir efetividade quando da aplicação do tão escasso recurso público (Oliveira \& Pisa, 2015).

Neste sentido, pesquisas internacionais se dedicaram a avaliar como a gestão na educação proporcionou uma trajetória de sucesso nos países da Ásia oriental, que ao longo dos últimos 40 anos passaram de condições semelhantes a de países africanos para uma das melhores do mundo, concluindo que a educação é considerada eficiente quando alcança altos índices de qualidade com um mínimo de contrapartida financeira (Tan \& Birger, 2008).

Assim, infere-se ser controversa a relação direta entre investimento e resultado para a sociedade, isso porque, há entre o investimento e o resultado, a atuação do gestor público como intermediador, que por um lado, possui uma legislação (CF/88) que o obriga a investir um percentual mínimo na saúde e educação, mas por outro, não lhe exige resultado objetivo desse investimento como requisito para emissão de parecer para aprovação de suas contas perante os Tribunais de Contas. 
Nesse seguimento, estudos como o de Ranis e Stewart (2005), já inferiram que, se os investimentos públicos forem aplicados de maneira ineficaz e desnecessária, causam transtornos a sociedade, portanto, devendo o gestor e os órgãos de controle atuarem de forma planejada, visando a verificação do atingimento de resultados desses investimentos através de indicadores (Scarpin \& Slomski, 2007).

Ante o exposto, considerando ser inadmissível que o já tão escasso recurso público seja desperdiçado em investimentos que não geram resultados para a sociedade, apresenta-se o estudo, que por meio de uma abordagem quantitativa, avalia o impacto dos investimentos em saúde e educação no Índice de Efetividade da Gestão Municipal - IEGM, no período de 2015 a 2017 nos 78 municípios do Estado do Espírito Santo.

\section{Referencial Teórico}

A Administração Pública destina-se, dentre outras, a satisfazer a necessidade coletiva, por meio da gestão dos valores oriundos da arrecadação tributária com o objetivo principal de proporcionar a população acesso eficiente a saúde e educação dentre outras necessidades (Souza, Melo, Silva, \& Araújo, 2012). Assim, surge a necessidade do acompanhamento e utilização de indicadores pelos gestores visando aferir se os investimentos realizados têm, de fato, impactado de forma eficaz, eficiente e efetiva a sociedade.

\section{Da relação investimento, eficiência, eficácia e efetividade}

Destaca-se que uma das atribuições do Estado é exercer a função alocativa, disponibilizando à sociedade, por exemplo, serviços que visam possibilitar à população maior bem-estar social nas dimensões saúde e educação (Costa, Ferreira, Braga, \& Abrantes, 2015), e em razão da escassez de recursos, no exercício desta função, deve o gestor alocá-los visando garantir o maior impacto social positivo possível (Pereira, Tannuri-Pianto, \& Sousa, 2010)

Esta relação entre gasto público, eficiência e eficácia é objeto de inúmeros estudos na literatura, encontrando-se diversos resultados, antagônicos entre si.

Corroborando a hipótese da pesquisa, de que quanto maiores os valores investidos em saúde e educação, melhores os índices de efetividade, depara-se na literatura internacional, com estudos como o de Greenwald, Hedges e Laine (1996), que ao analisarem escolas norte americanas encontraram como resultado de seu trabalho, que os recursos investidos pela escola estão relacionados positivamente com o desempenho dos alunos e que essas relações são grandes o suficiente para serem educativamente importantes. No estudo, também restou evidenciado que moderados aumentos com os gastos poderiam estar associados a aumentos significativos no desempenho. Além disso, variáveis de recursos que aplicados à capacitação dos professores também mostram relações muito fortes com o desempenho do aluno.

$\mathrm{Na}$ área da saúde, também se encontram estudos como o de Silva (2011), apontando que o baixo financiamento público associado a problemas não resolvidos de gestão e regulação públicas na saúde, compõe desafios que devem ser considerados na avaliação da integração da saúde no SUS.

$\mathrm{Na}$ seara internacional, a pesquisa de Solà e Prior (2001), apresenta uma análise sobre o desempenho de hospitais catalães no enfoque da eficiência, apontando que os hospitais mais eficientes foram aqueles que utilizaram maiores recursos especialmente em investimentos em tecnologia.

Entretanto, a literatura é bastante divergente no assunto, visto que, também se identificam estudos que encontraram evidências contrárias ao estudar eficiência de gastos municipais em saúde e educação. 
Neste sentido, o estudo de Faria, Januzzi e Silva (2008), constatou como resultado de pesquisa, que a eficiência não estaria relacionada a maior ou menor investimento de recursos, tendo encontrado ainda, municípios que investem mais, porém, gastam mal os seus recursos, ao passo que outros pouco investem, entretanto, ao investirem, o fazem de forma adequada, usando-os com eficiência. $\mathrm{Ou}$ seja, municípios menos favorecidos economicamente ou com menores percentuais de investimento podem ser mais eficientes nos gastos públicos com educação e saúde, enquanto municípios mais favorecidos e com maiores gastos, podem obter eficiência muito baixa.

Neste mesmo sentido, Rezende, Slomski e Corrar (2005), ao realizarem uma pesquisa exploratória diagnosticaram, por meio da análise de clusters, que municípios que realizaram maiores investimentos, necessariamente, não se encontravam no cluster dos que possuíam melhores índices de desenvolvimento humano. Nesta mesma pesquisa, também foi observado que a relação entre municípios que apresentam maiores IDH e municípios com maiores investimentos financeiros não repercutiu em uma relação linear, concluindo que os municípios que possuíam melhores índices de desenvolvimento humano não estavam relacionados tão somente ao fator investimento público.

Ainda na seara da eficiência, para Tanzi (2004), o investimento deve gerar benefícios máximos potenciais para a população, destacando que a eficiência se relaciona com a comparação entre entrada e saída ou entre custos e benefícios, ressaltando também a preocupação de instituições como o Banco Mundial e o Fundo Monetário Internacional - FMI com atividades governamentais consideradas improdutivas ou ineficientes.

\section{Índice de Efetividade da Gestão Municipal - IEGM}

O índice, segundo Siche, Agostinho, Ortega, \& Romeiro (2007), é entendido como um valor que realiza numericamente a tradução de uma realidade, e para a presente pesquisa, adota-se o Índice de Efetividade de Gestão Municipal - IEGM. Esse índice possui como principal objetivo medir o nível de desempenho de resultado, ou seja, ele afere dentre sete dimensões: educação, saúde, planejamento, gestão fiscal, meio ambiente, proteção dos cidadãos e tecnologia da Informação, a efetividade das políticas e atividades desenvolvidas pelos seus gestores (TCESP \& IEGM, 2014), lembrando que essas dimensões foram selecionadas a partir de sua posição estratégica no contexto das finanças públicas dos municípios.

Segundo o Manual do IEGM - TCEES (2018), tratando-se o IEGM como índice anual, inicialmente, elaborado por técnicos do Tribunal de Contas do Estado de São Paulo, após assinatura de termo de cooperação técnica, se tornou o IEGM Brasil, hoje adotado por todos os Tribunais de Contas estaduais do país.

Cada uma das sete dimensões possui um questionário próprio, e anualmente são encaminhados aos chefes do executivo municipal para serem preenchidos eletronicamente. Após o encerramento do prazo para as respostas e envio dos dados, os Tribunais de Contas avaliam a possibilidade de validar os dados, enviando aos municípios, servidores do corpo técnico especializado para verificação dos dados declarados nos questionários (Manual IEGM - TCEES (2018).

Observa-se que no estado do Espirito Santo, não houve validação dos dados no ano de 2015, entretanto, no ano de 2016, os dados referentes aos questionários de Saúde e Educação, foram validados em 21 dos 78 municípios, e no ano de 2017, a validação ocorreu em todos os municípios do Estado nas referidas dimensões. (TCEES - Anuário, 2018).

No que tange a divulgação dos resultados, segundo o Manual do IEGM (TCEES, 2018), por se tratar de sete dimensões, o resultado é divulgado individualmente para cada uma dessas dimensões e no seu resultado geral, que compreende a média das dimensões. Para o cálculo do resultado do índice, é realizada a combinação dos seguintes itens: "Dados governamentais; Dados de prestação 
de contas e de Informações levantadas a partir de questionários preenchidos pelas Prefeituras Municipais" (Manual IEGM TCEES, 2018, p. 03).

Especificamente quanto à dimensão educação, o indicador que compõe o IEGM é o "IEDUC", e os quesitos, específicos de gestão municipal, são relativos à educação infantil, creches e pré-escolas e Ensino Fundamental, cujos indicadores estabelecem uma métrica das ações sobre a gestão da Educação Pública Municipal na sua esfera de responsabilidade, que impactam diretamente a qualidade dos serviços e a vida dos munícipes (Manual TCEES, 2018).

Quanto ao "ISAÚDE", os quesitos se referem à gestão municipal da Saúde voltados à Atenção Básica, e os resultados permitem a classificação dos municípios "a partir de indicadores que estabeleçam uma métrica das ações sobre a gestão da Saúde Pública Municipal, na esfera de responsabilidade municipal, que impactam a qualidade dos serviços e a vida das pessoas" (Manual IEGM TCEES, 2018, p. 08).

No que tange a análise dos dados e resultados, ressaltamos que são definidos em razão da consolidação das notas obtidas pelo município nos sete índices setoriais. Esses resultados são gerados em "faixas" com a seguinte classificação:

- "Nota A: Faixa Altamente efetiva - IEGM com IEGM com pelo menos $90 \%$ da nota máxima e, no mínimo, 5 índices com nota $A$.

- $\quad$ Nota B+: Faixa Muito efetiva - IEGM entre 75,0\% e 89,9\% da nota máxima.

- $\quad$ Nota B: Faixa efetiva - IEGM entre $60,0 \%$ e $74,9 \%$ da nota máxima.

- Nota C+: Faixa em fase de adequação - IEGM entre 50,0\% e 59,9\% da nota máxima.

- Nota C: Faixa Baixo Nível de adequação - IEGM menor ou igual a 49,9\%." (Manual IEGM TCEES, 2018, pg. 74)

Por fim, destaca-se que o Índice da Educação Básica - IDEB, conceituado como indicador de desempenho educacional (Fernandes, 2007), também será utilizado como variável de controle, para a Educação.

Os elementos referenciados teoricamente, servirão de base para que possamos responder à questão de pesquisa, já que, através da análise das notas alcançadas pelos municípios no IEGM e dos investimentos realizados, será possível aferir se os investimentos têm gerado resultados efetivos, impactando positivamente a vida da população nos municípios em relação a saúde e educação.

\section{Metodologia da Pesquisa}

\section{Delimitação, coleta e tratamento dos dados}

Para fins de delimitação da amostra, optou-se por realizar os estudos com base nos dados relativos aos municípios do Estado do Espírito Santo. As informações concernentes ao investimento per capita na saúde e investimento por aluno na educação, aplicado por cada um dos 78 municípios do Estado do Espírito Santo, foram obtidas por meio do sistema "CIDADES", disponibilizado no site oficial do Tribunal de Contas do Estado do Espírito Santo.

Quanto ao indicador, optou-se para a consecução do trabalho, pelo Índice de Efetividade de Gestão Municipal - IEGM, por ser aplicado por todos os Tribunais de Contas do Brasil e por permitir parâmetros de comparabilidade para a realização de pesquisas futuras, tendo seus dados, sido extraídos do site oficial do Instituto Rui Barbosa - IRB.

O presente estudo possui como limitação temporal os anos de 2015, 2016 e 2017, em razão de serem os anos em que o TCEES divulgou, até a realização da presente pesquisa, o resultado do indicador adotado. 
Como variável de controle para os testes estatísticos relativos à educação, utiliza-se o IDEB (dados disponibilizados pelo portal do MEC), referente a seu resultado em "educação básica/ensino fundamental em anos iniciais", ressaltando que, diferente do IEGM (que possui divulgação de resultado anual), o resultado do IDEB é divulgado a cada 2 anos, por isso realiza-se média entre os resultados de 2015 e 2017 e considera-se seu resultado para o ano de 2016.

No que tange ao tratamento dos dados, submete-se todas as variáveis a winsorização a $1 \%$ para eliminação de possíveis outliers. Importa frisar que, quanto a possíveis problemas relacionados a heterocedasticidade do modelo, utiliza-se o estimador de White, cuja utilização é capaz de corrigir as variâncias dos coeficientes fazendo com que os testes voltem a ser confiáveis mesmo na presença de heterocedasticidade, tornando confiáveis os resultados dos testes de hipóteses.

Para a realização dos testes de hipótese, a primeira etapa foi criar variáveis dummies, para isso, os municípios foram divididos entre aqueles considerados efetivos (notas no IEGM acima de $60 \%$ e, portanto, aqueles que se encontram classificados nas faixas de resultado $\mathrm{A}, \mathrm{B}+\mathrm{e} \mathrm{B}$ ) e não efetivos (aqueles com índice de efetividade abaixo de 59\%, portanto classificados nas faixas $\mathrm{C}+$ e $\mathrm{C}$ ), ressaltando-se que o objetivo destas variáveis dummies é verificar se o nível de investimento é diferente a depender se o município se encontra na parte efetiva ou não efetiva deste ranking.

Visando fornecer maior robustez aos resultados, repete-se o teste de hipótese considerando nas variáveis dummies, apenas os resultados extremos, ou seja, os municípios foram divididos novamente em dois grupos, o primeiro com os municípios mais efetivos (aqueles classificados nas faixas $\mathrm{A}$ e $\mathrm{B}+$ ) e o segundo com os piores resultados de efetividade (classificados na faixa $\mathrm{C}$ ).

\section{Modelos e estimadores}

Os seis modelos de regressão foram estimados por meio do método Tobit, que se trata de extensão do modelo de regressão linear, mas que por possuir partes constantes, trata-se de interpelação necessária para lidar com disfunções de dados censurados (Johnston \& DiNardo, 1972). Destacase que a variável dependente utilizada (IEGM), possui valores limitados, portanto, caso fosse adotado um modelo linear para a estimação, poderiam ser estimados valores negativos (Wooldridge, 2016).

No presente estudo, a variável dependente utilizada nos modelos de regressão é o Índice de Efetividade de Gestão Municipal - IEGM, que varia de 0 a 1, portanto, não poderia assumir valores negativos. Assim, devido à restrição contida no modelo linear, adota-se o modelo Tobit desenvolvido nos seguintes termos:

Modelo 1:

$I E G M_{i t}=\beta_{0}+\beta_{1}$ educ. al $l_{i t}+\beta_{2}$ saude. cap $_{i t}+E_{i t}$

O primeiro modelo busca avaliar a efetividade de maneira geral (IEGM total), considerando o investimento dos municípios capixabas em saúde per capita e investimento em educação por aluno. Em que:

$I E G M_{i t}=$ IEGM total

$\beta_{1}$ educ. $a l_{i t}=$ Investimento em educação por aluno.

$\beta_{2}$ saude. cap $_{i t}=$ Investimento em saúde per capita.

$E_{i t}=$ Erro

Modelo 2:

IEGM $_{i t}=\beta_{0}+\beta_{1}$ educ. al $i t+\beta_{2}{\text { saude. } \text { cap }_{i t}+\beta_{3} \text { educ.al }}_{i t-1}+\beta_{4}$ saude.cap $_{i t-1}+E_{t}$ 
$I E G M_{i t}=$ IEGM total

$\beta_{1}$ educ. $a l_{i t}=$ Investimento em educação por aluno.

$\beta_{2}$ saude. cap $_{i t}=$ Investimento em saúde per capita.

$\beta_{3} e d u c \cdot a l_{i t-1}=$ Investimento em educação por aluno no exercício anterior.

$\beta_{4}$ saude. cap $_{i t-1}=$ Investimento em saúde per capita no exercício anterior.

$E_{i t}=$ Erro

Este modelo visa controlar os resultados encontrados no Modelo 1 considerando se o investimento realizado no exercício anterior estaria gerando impacto na efetividade no exercício seguinte.

Modelo 3:

$I E D U C_{i t}=\beta_{0}+\beta_{1}$ educ. al $i t+\beta_{2} I D E B_{i t}+E_{i t}$

$I E D U C_{i t}=$ Índice de efetividade da gestão municipal em Educação.

$\beta_{1}$ educ. $a l_{i t}=$ Investimento em educação por aluno.

$\beta_{2} I D E B_{i t}=$ Índice de Desenvolvimento da Educação Básica

$E_{i t}=$ Erro

Por meio deste modelo, busca-se realizar teste de regressão considerando a efetividade dos municípios apenas no que tange a Educação utilizando-se como variável de controle o IDEB.

Modelo 4:

$I E D U C_{i t}=\beta_{0}+\beta_{1} e d u c . a l_{i t}+\beta_{2} e d u c \cdot a l_{t-1}+\beta_{3} I D E B_{i t}+E i_{i}$

$I E D U C_{i t}=$ Índice de efetividade da gestão municipal em Educação.

$\beta_{1}$ educ. $a l_{i t}=$ Investimento em educação por aluno.

$\beta_{2} e d u c . a l_{t-1}=$ Investimento em educação por aluno no exercício anterior

$\beta_{3} I D E B_{i t}=$ Índice de Desenvolvimento da Educação Básica

$E_{i t}=$ Erro

Este modelo visa controlar os resultados encontrados no modelo 3 considerando se o investimento em educação por aluno realizado no exercício anterior estaria gerando impacto na efetividade da educação no exercício seguinte.

Modelo 5:

$I S A U D E_{i t}=\beta_{0}+\beta_{1}$ saude. $\operatorname{cap}_{i t}+E i_{i}$

$I S A U D E_{i t}=$ Índice de efetividade da gestão municipal em Saúde

$\beta_{1}$ saude. cap $_{i t}=$ Investimento em saúde per capita.

$E_{i t}=$ Erro

O Modelo busca realizar teste de regressão quanto à efetividade dos municípios, especificamente na saúde, considerando o investimento per capita dos municípios.

Modelo 6:

$I S A U D E_{i t}=\beta_{0}+\beta_{1}$ saude.perca $_{i t}+\beta_{2}{\text { saude. } \text { cap }_{t-1}+E i_{i}}$

$I S A U D E_{i t}=$ Índice de efetividade da gestão municipal em Saúde

$\beta_{1}$ saude. cap $_{i t}=$ Investimento em saúde per capita.

$\beta_{2}$ saude. $\operatorname{cap}_{t-1}=$ Investimento em saúde per capita no exercício anterior.

$E_{i t}=$ Erro

Este modelo visa controlar os resultados encontrados no modelo 5, considerando se o investimento realizado no exercício anterior em saúde per capita estaria gerando impacto na efetividade da saúde no município no exercício seguinte. 


\section{Análise dos Resultados}

O objetivo do presente trabalho é averiguar o impacto dos investimentos em saúde e educação no Índice de Efetividade da Gestão Municipal - IEGM, no período de 2015 a 2017, abrangendo em sua amostra de pesquisa todos os municípios do Estado do Espírito Santo, partindo da hipótese de que quanto maiores os valores investidos em saúde por habitante e em educação por aluno, melhores os índices de efetividade.

Buscando alcançar o objetivo de pesquisa, após o levantamento dos dados e aplicação da metodologia, apresenta-se o resultado, cuja exposição se dará em quatro etapas: caracterização da amostra, análise de correlação, teste de hipótese e regressão.

\section{Caracterização da amostra}

Antes da elaboração da tabela descritiva, submetem-se todas as variáveis à winsorização a 1\% (um por cento).

Tabela 1: Estatística descritiva

\begin{tabular}{lcccccccc}
\hline variáveis & Observações & Média & coef. var. & mínimo & $\mathbf{1}^{\circ}$ quartil & Mediana & 3 $^{\circ}$ quartil & Máximo \\
\hline \hline IEGM & 233 & 0.572 & 0.114 & 0.420 & 0.530 & 0.572 & 0.620 & 0.723 \\
IEDUC & 233 & 0.615 & 0.191 & 0.380 & 0.520 & 0.610 & 0.710 & 0.850 \\
ISAUDE & 233 & 0.627 & 0.233 & 0.290 & 0.520 & 0.640 & 0.730 & 0.900 \\
IDEB & 234 & 5.716 & 0.0885 & 4.100 & 5.400 & 5.700 & 6 & 6.800 \\
educ.al & 234 & 3895 & 0.466 & 1729 & 2781 & 3437 & 4631 & 11800 \\
saúde cap & 234 & 359.9 & 0.408 & 155.6 & 264.1 & 340.0 & 424.5 & 1195 \\
\hline
\end{tabular}

Fonte: Elaborado pelo autor.

A tabela descritiva apresenta-se com baixo coeficiente de variação, logo, o IEGM total não se revelou excessivamente discrepante entre os municípios (11\%), porém, avaliando-se a efetividade na saúde (ISAUDE) e na educação (IEDUC) encontra-se uma variação mais elevada na efetividade, sendo ainda maior na saúde $(23 \%)$. Esta heterogeneidade na saúde se reflete quando da análise dos quartis e mediana, sendo possível constatar como mínimo em efetividade a pontuação de 29 e máximo é 90.

Quanto ao investimento per capita em saúde e por aluno em educação, em média, os municípios do Estado do Espírito Santo investiram, nos três anos avaliados, R $\$ 3.895$ (três mil, oitocentos e noventa e cinco reais) por aluno em educação e $\mathrm{R} \$ 359.9$ (trezentos e cinquenta e nove reais e noventa centavos) per capita em saúde.

Quanto aos quartis, nos valores investidos em saúde e educação, a maior discrepância se encontra nos investimentos realizados pelos municípios em educação, onde os investimentos mínimos (referente ao primeiro quartil) foi de $\mathrm{R} \$ 1.729,00$ (mil setecentos e vinte e nove reais) por aluno, e o investimento e o máximo de $\mathrm{R} \$ 11.800,00$ (onze mil e oitocentos reais).

Em relação a variável de controle, IDEB, a média entre os municípios foi de 5.7 , não se manifestando tão discrepante, já que, $50 \%$ da amostra possui nota no IDEB acima da média e o os outros $50 \%$ abaixo da média. Desta forma, quando se verifica o IDEB, é possível perceber que, embora existam municípios que tenham investido cerca de sete vezes mais em educação por aluno, as notas possuem um baixo percentual de dispersão (apenas 8\%), não havendo diferença considerável nas notas entre os Municípios que investem mais para os que e investem menos.

\section{Análise de Correlação}

Nesta etapa dos resultados, processa-se teste correlação a fim de verificar quais correlações são significativas entre as variáveis presentes nos modelos utilizados na pesquisa, onde foi possível 
encontrar, com 95\% de confiança, a existência de correlação entre as variáveis IEDUC, ISAUDE e IEGM. No que tange ao ISAUDE, o teste apontou correlação entre este e os investimentos na saúde e na educação.

Tabela 2: Correlação entre as variáveis

\begin{tabular}{|c|c|c|c|c|c|c|}
\hline Variáveis & IEGM & IEDUC & ISAUDE & educ.al & Saúde.cap & IDEB \\
\hline$\overline{\text { IEGM }}$ & 1 & & & & & \\
\hline IEDUC & $0.6029 *$ & 1 & & & & \\
\hline ISAUDE & $0.5813^{*}$ & 0.124 & 1 & & & \\
\hline educ.al & 0.0516 & -0.0442 & $0.1806^{*}$ & 1 & & \\
\hline saúde. cap & 0.0765 & 0.0467 & $0.1611^{*}$ & $0.6605^{*}$ & 1 & \\
\hline IDEB & 0.0916 & -0.112 & -0.00390 & 0.0582 & 0.0272 & 1 \\
\hline
\end{tabular}

*Existência de correlação

Fonte: Elaborado pelo autor.

\section{Teste de hipótese}

Com o teste de hipótese demonstrado na Tabela 3 (teste de média entre grupo de municípios efetivos e não efetivos na educação), demonstra-se que os três resultados para o valor $p$ se apresentaram acima de 10\%, o que significa que em nenhum dos casos rejeita-se Ho, assim sendo, não evidencia-se que o investimento em educação nos municípios considerados efetivos é menor que nos não efetivos, que nos efetivos é diferente de nos considerados não efetivos ou que nos efetivos seja maior que nos não efetivos.

Visando fornecer maior robustez nos resultados, reiteram-se os testes de hipótese (Tabela 4), entretanto, considerando apenas os municípios mais efetivos em educação (classificados com notas $\mathrm{A}$ e $\mathrm{B}+$ ) e os que apresentaram os piores resultados no IEDUC (classificados com nota $\mathrm{C}$ ), o resultado se manteve, assim, a única evidencia que se pode constatar dos testes de hipótese realizados é que na educação, independentemente de se estar no grupo efetivo ou não efetivo, o investimento médio por aluno é o mesmo.

Tabela 3: Teste de média entre grupos de municípios efetivos e não efetivos na educação

\begin{tabular}{ccccc}
\hline \multicolumn{5}{c}{ Painel A: Teste para educação } \\
\hline & $\begin{array}{c}\text { H0: média(efetivo) }=\text { média (não efetivo) } \\
\text { H1: média(efetivo) }<\text { média } \\
\text { (não efetivo) }\end{array}$ & $\begin{array}{c}\text { Hédia(efetivo) } \neq \text { média } \\
\text { (não efetivo) }\end{array}$ & $\begin{array}{c}\text { H1: média(efetivo) }>\text { média } \\
\text { (não efetivo) }\end{array}$ & $\begin{array}{c}\text { Teste de } \\
\text { variância }\end{array}$ \\
\hline \hline $\begin{array}{c}\text { Valo } \\
\text { r p }\end{array}$ & 0.65 & 0.70 & 0.35 & 0.1728 \\
\hline \hline
\end{tabular}

Fonte: Elaborado pelo autor.

Tabela 4: Teste de média entre os grupos de municípios mais efetivos e os menos efetivos na educação

\begin{tabular}{|c|c|c|c|}
\hline \multicolumn{4}{|c|}{ Painel B: Teste para educação } \\
\hline \multicolumn{4}{|c|}{ H0: média(maior) = média (menor) } \\
\hline $\begin{array}{l}\text { H1: média(maior) }<\text { média } \\
\text { (menor) }\end{array}$ & $\begin{array}{l}\text { H1: média(maior) } \neq \text { média } \\
\text { (menor) }\end{array}$ & $\begin{array}{l}\text { H1: média(maior) }>\text { média } \\
\text { (menor) }\end{array}$ & $\begin{array}{l}\text { Teste de } \\
\text { variância }\end{array}$ \\
\hline Valor P & 0.4406 & 0.2203 & 0.6677 \\
\hline
\end{tabular}

Fonte: Elaborado pelo autor

No que tange à saúde, também se realizam dois testes de hipóteses, e em ambos, (tabela 5 e 6), os resultados evidenciaram que tanto a média quanto a variância são estatisticamente diferentes entre os dois grupos criados, e que, em média, o grupo dos municípios que está entre os efetivos (A, B+ e B) investe menos em saúde do que o grupo de municípios considerados não efetivos (classificados com notas $\mathrm{C}+\mathrm{e} \mathrm{C})$. 
Tabela 5: Teste de média entre grupos de municípios efetivos e não efetivos na saúde

\begin{tabular}{|c|c|c|c|}
\hline \multicolumn{4}{|c|}{ Painel B: Teste para saúde } \\
\hline \multicolumn{4}{|c|}{ H0: média(efetivo) = média (não efetivo) } \\
\hline $\begin{array}{l}\text { H1: média (efetivo) }<\text { média } \\
\text { (não efetivo) }\end{array}$ & $\begin{array}{l}\text { H1: média (efetivo) } \neq \text { média } \\
\text { (não efetivo) }\end{array}$ & $\begin{array}{l}\text { H1: média(efetivo) }>\text { média } \\
\text { (não efetivo) }\end{array}$ & $\begin{array}{l}\text { Teste de } \\
\text { variância }\end{array}$ \\
\hline Valor $\mathrm{p}$ & & & \\
\hline 0.0 & 0.0 & 1.0 & 0.9257 \\
\hline
\end{tabular}

Fonte: Elaborado pelo autor.

Tabela 6: Teste de média entre os grupos de municípios mais efetivos e os menos efetivos na saúde

\begin{tabular}{|c|c|c|c|}
\hline \multicolumn{4}{|c|}{ Painel : Teste para saúde } \\
\hline \multicolumn{4}{|c|}{ H0: média(maior) = média (menor) } \\
\hline $\begin{array}{l}\text { H1: média(maior) }<\text { média } \\
\text { (menor) }\end{array}$ & $\begin{array}{l}\mathrm{H} 1: \text { média(maior) } \\
(\text { (menor) }\end{array}$ & $\begin{array}{c}\text { H1: média(efetivo) }>\text { média (não } \\
\text { efetivo) }\end{array}$ & $\begin{array}{l}\text { Teste de } \\
\text { variância }\end{array}$ \\
\hline $\begin{array}{l}\text { Valor } \mathrm{p} \\
0.0076\end{array}$ & 0.0151 & 0.9924 & 0.00 \\
\hline
\end{tabular}

Fonte: Elaborado pelo autor.

Deste modo, após os testes de hipótese evidencia-se que na educação, seja no grupo de municípios considerados efetivos ou não efetivos, as médias de investimentos são iguais, não havendo diferença no nível de investimento a depender se o município é efetivo ou não, quanto aos testes relativos à saúde, estes evidenciaram que, o grupo de municípios classificados como efetivos, investem em média menos do que os municípios considerados não efetivos.

\section{Regressão}

Visando fornecer maior robustez aos resultados, estimam-se os seis modelos de regressão em tobit, optando-se também, por manter o estimador de Pooled (MQO agrupado para painel) para fins de comparação de resultados.

Abaixo de cada coeficiente, encontram-se os seus respectivos erros padrão. Coeficientes marcados com uma estrela $(*)$ são estatisticamente significativos com $10 \%$ de significância, coeficientes marcados com duas estrelas (**) são estatisticamente significativos com $5 \%$ de significância e finalmente, coeficientes marcados com três estrelas (***) são estatisticamente significativos com $1 \%$ de significância. Os resultados dos testes de Hausman são apresentados pelo valor p do mesmo e o estimador utilizado é indicado em cada caso.

A Tabela 7 representa os modelos que buscam analisar o IEGM geral, enquanto as Tabelas 8 e 9 explicam o IEGM associados à educação e saúde, respectivamente.

Tabela 7: Modelos para IEGM geral

\begin{tabular}{lllllll}
\hline \multicolumn{7}{c}{ Variável dependente: IEGM } \\
\hline \hline educ.al & -5.98 & -6.36 & -6.36 & -2.89 & -2.91 & -2.91 \\
& -0.160 & -0.150 & -0.160 & -0.420 & -0.470 & -0.420 \\
saude.cap & 1.93 & 1.87 & 1.87 & -6.81 & -6.78 & -6.78 \\
& 0.410 & 0.390 & 0.390 & -0.880 & -0.770 & -0.860 \\
lag educ.al & & & 4.77 & 4.77 & 4.77 \\
& & & 0.670 & 0.780 & 0.660 \\
lag saúde.cap & & & 9.99 & 9.99 & 9.99 \\
& & & & 1.260 & 1.330 & 1.240 \\
constante & $0.567 * * *$ & $0.567 * * *$ & $0.567 * * *$ & $0.547 * * *$ & $0.547 * * *$ & $0.547 * *$ \\
& 35.43 & 44.47 & 35.04 & 29.90 & 37.15 & 29.36 \\
\hline \hline Observações & 233 & 233 & 233 & 155 & 155 & 155 \\
Estimador & tobit & pooled & efeito aleatório & tobit & pooled & efeito aleatório \\
\hline Nota: $*$ significância de $10 \% ; * *$ significância de $5 \%$; *** significância de $1 \%$ & & \\
Fonte: Elaborado pelo autor. & & & & &
\end{tabular}


$\mathrm{Da}$ análise dos resultados referentes ao modelo do IEGM nota geral, infere-se que, independentemente do estimador utilizado (tobit ou pooled), o investimento por aluno em educação e o investimento per capita em saúde não se mostraram significativos em nenhum dos níveis de significância.

Para este modelo, ao testar usando o efeito aleatório (que foi o escolhido após o teste de Hausman), observa-se que ainda assim o resultado se manteve, ou seja, o investimento em educação ou em saúde, não está exercendo qualquer efeito no nível de efetividade em geral, contrariando a hipótese de que quanto maiores os investimentos melhores seriam os índices de efetividade.

Ainda assim, após esta análise, opta-se por controlar este resultado pelos investimentos realizados no exercício anterior. Desta forma, avalia-se se o investimento não estaria gerando impacto na efetividade no mesmo exercício, mas sim no seguinte, entretanto, da análise dos dados, depreendese que o resultado se manteve na mesma direção, logo, esses controles não foram significativos, ou seja, investir mais no ano avaliado em efetividade, ou no ano anterior, não interferiu na efetividade.

O próximo passo foi realizar os mesmos testes isoladamente para efetividade na educação IEDUC (Painel 8) e posteriormente na saúde - ISAUDE (Painel 9).

Tabela 8: Modelos para o IEDUC

\begin{tabular}{lllllll}
\hline \multicolumn{7}{c}{ Variável dependente: IEDUC } \\
\hline \hline educ.al & $-3.38 \mathrm{e}-06$ & $-3.41 \mathrm{e}-06$ & $-3.41 \mathrm{e}-06$ & $-1.26 \mathrm{e}-05$ & $-1.26 \mathrm{e}-05$ & $-3.39 \mathrm{e}-05$ \\
& -0.630 & -0.670 & -0.630 & -0.890 & -1.040 & -1.270 \\
IDEB & -0.0344 & -0.0346 & -0.0346 & -0.0176 & -0.0178 & -0.0211 \\
& -1.970 & -2.140 & -1.970 & -0.900 & -0.950 & -0.650 \\
lag educ.al & & & $9.70 \mathrm{e}-06$ & $9.65 \mathrm{e}-06$ & $-1.16 \mathrm{e}-05$ \\
& & & 0.690 & 0.800 & -0.480 \\
constante & 0.825 & 0.826 & 0.826 & 0.715 & 0.716 & 0.900 \\
& 8.150 & 8.590 & 8.140 & 6.230 & 6.280 & 4.400 \\
\hline \hline Observações & 233 & 233 & 233 & 155 & 155 & 155 \\
Estimador & tobit & pooled & efeito aleatório & tobit & pooled & efeito fixo \\
\hline
\end{tabular}

Nota: * significância de $10 \%$; ** significância de $5 \%$; *** significância de $1 \%$

Fonte: Elaborado pelo autor.

Os modelos para avaliar a educação, foram controlados pela nota no IDEB, que poderia estar atrelada diretamente a análise da efetividade na educação. No estudo dos modelos, independente do estimador (tobit, pooled ou efeito aleatório) o investimento por aluno não se mostrou significativo, ou seja, constata-se que o investimento não mostrou interferência na efetividade na educação.

Tabela 9: Modelos para ISAUDE

\begin{tabular}{lcccccc}
\hline \multicolumn{7}{c}{ Variável dependente: ISAUDE } \\
\hline \hline saude.cap & $0.000135^{*}$ & -0.000400 & $0.000133^{*}$ & -0.000236 & -0.000237 & -0.000237 \\
& 1.750 & -1.630 & 1.720 & -1.060 & -1.020 & -1.050 \\
lag saude.cap & & & $0.000372^{*}$ & $0.000372^{*}$ & $0.000372^{*}$ \\
& & & 1.720 & 1.680 & 1.700 \\
Constante & $0.579 * * *$ & $0.772^{* * *}$ & $0.580^{* * *}$ & $0.557^{* * *}$ & $0.557 * * *$ & $0.557^{* * *}$ \\
& 19.33 & 8.690 & 19.21 & 16.63 & 21.21 & 16.45 \\
\hline \hline Observações & 233 & 233 & 233 & 155 & 155 & 155 \\
Estimador & tobit & pooled & efeito fixo & tobit & pooled & efeito aleatório \\
\hline
\end{tabular}

Nota: * significância de $10 \%$; ** significância de $5 \%$; *** significância de $1 \%$

Fonte: Elaborado pelo autor.

Por fim, ao se analisar a efetividade na saúde (Tabela 9), percebe-se que, quando o modelo foi estimado usando apenas o investimento em saúde per capita no mesmo ano em que se avalia a efetividade, essa foi significativa e com sinal positivo, porém, quando o resultado foi controlado 
pela defasagem da variável (controlado pelo período passado), o investimento presente deixou de ser significativo e apenas o lag passou a ser com sinal positivo, o que indica que, em média, o que afeta o ISAUDE não é o investimento presente, mas o investimento na data passada e de forma positiva. Assim, se o gestor investisse mais em saúde, no ano seguinte, este investimento geraria mais efetividade.

Assim sendo, a evidência encontrada no presente estudo é que, na educação, os investimentos por aluno realizados pelos municípios capixabas (2015 a 2017) não tem impactado a efetividade segundo o Índice de Efetividade de Gestão Municipal, ainda que, controlado pelo IDEB, e este investimento por aluno, também não evidenciou qualquer efeito na efetividade (IEDUC) se o investimento tivesse sido realizado no ano anterior.

Dessa forma, verifica-se que as evidências encontradas no presente estudo em educação, apresentaram-se contrárias ao resultado do estudo de Greenwald et al. (1996), que haviam concluído que os recursos investidos pela escola estariam relacionados positivamente com o desempenho dos alunos.

Na saúde, restou evidenciado, especialmente após os testes de regressão, que o investimento per capita em saúde pelos municípios do Estado do Espírito Santo nos anos de 2015 a 2017 repercutiram positivamente na efetividade (ISAUDE), no exercício seguinte, mas não no mesmo exercício avaliado pelo IEGM.

\section{Considerações Finais}

Partindo da hipótese de que quanto maior o investimento em saúde e educação, melhores os índices de efetividade, o presente trabalho teve como objetivo verificar o impacto entre o investimento per capita em saúde e o investimento por aluno em educação, no Índice de Efetividade da Gestão Municipal - IEGM, no período de 2015 a 2017, abrangendo em sua amostra de pesquisa todos os municípios do Estado do Espírito Santo.

Para a consecução do objetivo de pesquisa, realizam-se testes de correlação, de hipótese e regressão. Para os testes de hipóteses, agrupam-se os municípios em dummies de municípios efetivos e não efetivos segundo o IEGM, inferindo-se da análise de resultados que, em ambos os grupos, a média de investimento na saúde e na educação é a mesma, notando-se indicativo de que os resultados contrariariam a hipótese da pesquisa.

Para a regressão, visando fornecer maior robustez aos resultados, os modelos foram estimados a partir de tobit e Mínimos Quadrados Ordinários (MQO), e os estimadores considerados foram o de efeito fixo e de efeito aleatório, escolhendo-se o mais adequado para cada modelo, a partir do teste de Hausman.

Da análise dos resultados, restou evidenciado que, na educação, os investimentos por aluno realizados pelos municípios capixabas (2015 a 2017), não tem impactado positiva ou negativamente na efetividade da educação aferida pelo Índice de Efetividade de Gestão Municipal, independente se o investimento tenha sido realizado no mesmo ano ou no ano anterior. Quanto à saúde, a evidência, encontrada é que os investimentos per capita, repercutiram positivamente na efetividade (ISAUDE), no exercício seguinte, mas não no mesmo exercício avaliado pelo IEGM.

As evidências encontradas no estudo contrariam a hipótese de que quanto maiores os investimentos melhores seriam os índices de efetividade, e leva-se por consequência a concluir, conforme apontam outros estudos como o de Zoghbi, Matos, Rocha, \& Arvate (2009), ser a gestão desses valores investidos, ou seja, a forma como são investidos estes valores, pelos gestores, que tem implicado em diferentes resultados de efetividade, entre um município e outro. 
Estudos como o de Hanushek (1986), já apontavam no mesmo sentido ao evidenciar que as escolas públicas são geridas de diferentes formas, o que poderia implicar em resultados diferentes, já que os recursos estariam sendo aplicados de forma diversa. No mesmo sentido, Menezes-Filho e Amaral (2009), destacam como principal conclusão do trabalho, não existir relação entre gastos na educação e desempenho escolar, ou seja, os estudos apontam para a gestão como o diferencial nos resultados e não para os valores investidos.

Assim sendo, a ausência de relação entre o investimento e a efetividade aferida pelo IEGM pode ser atribuída à exiguidade de decisões lastreadas em parâmetros adequados pelo gestor na tomada de decisão para alocação destes investimentos, levando, por consequência, a resultados ineficientes.

Esta atuação não parametrizada pelos gestores acaba por ser endossada pela legislação quando estabelece percentuais mínimos de investimentos a serem cumpridos como requisito para emissão de parecer favorável para aprovação das contas perante os Tribunais de Contas, mas não determinam a obrigatoriedade de que os investimentos devam refletir em indicadores de eficiência ou efetividade.

Neste sentido, considerando as atribuições Constitucionais atribuídas aos Tribunais de Contas pela Constituinte (CF, 1988), onde possuem papel fundamental para que o país alcance os objetivos fundamentais da República (Art. $3^{\circ}$ da CF/88), ressaltamos que os Tribunais têm exercido seu papel ao longo dos últimos anos, entretanto, conforme Dall'olio (2018), esta forma de atuação dos referidos Tribunais não é estanque, e os atuais modelos de administração pública voltados para governança pública acabam por impor que haja uma evolução na forma de atuação dos Tribunais.

Como limitações do trabalho, considera-se: (i) a análise apenas dos anos de 2015, 2016 e de 2017 (ii) limitação aos municípios do Estado do Espírito Santo. Como sugestão de pesquisa futura, sugere-se replicar o estudo considerando os resultados do IEGM antes e após a validação das questões pelos Tribunais de Contas, e avaliação com maior lapso temporal a fim de verificar se os resultados apresentarão a mesma tendência da presente pesquisa, sugere-se por fim, realização de pesquisa qualitativa visando identificar, nos municípios, as diferenças na gestão do recurso público que possibilitaram melhores índices de efetividade.

\section{Referências}

Caetano, C. C. R., Ávila, L. A. C., \& Tavares, M. (2017). A relação entre as transferências governamentais, a arrecadação tributária própria e o índice de educação dos municípios do estado de Minas Gerais. RAP - Revista de Administração Pública, 51(5), 897-916. Recuperado em 5 nov., 2018, em http://bibliotecadigital.fgv.br/ojs/index.php/rap/article/view/72431.

Constituição da República Federativa do Brasil. (1988). Brasília, DF: Senado Federal: Centro Gráfico. $\begin{array}{lllll}\text { Recuperado em } & 18 & \text { nov., } & \text { em }\end{array}$ https://www.planalto.gov.br/ccivil 03/Constituicao/Constituicao.htm .

Costa, C. C. de M., Ferreira, M. A. M., Braga, M. J., \& Abrantes, L. A. (2015). Fatores associados à eficiência na alocação de recursos públicos à luz do modelo de regressão quantílica. Revista de Administração Pública, 49(5), 1319-1347. Recuperado em 08 dez., 2018, em http://bibliotecadigital.fgv.br/ojs/index.php/rap/article/view/54994/53688 .

Dall'olio, L. L. dos S. (2018). Indicadores de efetividade no contexto das auditorias dos Tribunais de Contas. Cadernos, 1(2), 70-83. Recuperado em 23 jan., 2019, em https://www.tce.sp.gov.br/epcp/cadernos/index.php/CM/article/view/36/34 .

Faria, F. P., Jannuzzi, P. D. M., \& Silva, S. J. D. (2008). Eficiência dos gastos municipais em saúde e educação: uma investigação através da análise envoltória no estado do Rio de Janeiro. Revista de administração pública, 42(1),155-177 Recuperado em 01 jan., 2019, em http://repositorio.unicamp.br/bitstream/REPOSIP/16131/1/S0034-76122008000100008.pdf . Fernandes, R. (2007). Índice de desenvolvimento da educação básica (IDEB). Brasília: Ministério da 
Educação.

Greenwald, R., Hedges, L. V., \& Laine, R. D. (1996). The effect of school resources on student achievement. Review of Educational Research, 66(3), 361-396. Recuperado em 01 jan., 2019, em https://journals.sagepub.com/doi/abs/10.3102/00346543066003361.

Hanushek, E. A. (1986). The economics of schooling: Production and efficiency in public schools. Journal of Economic Literature, 24(3), 1141-1177. Recuperado em 10 de mar., 2019, em http://hanushek.stanford.edu/sites/default/files/publications/Hanushek $\% 201986 \% 20 J E L \% 202$ 4(3).pdf .

IRB - Instituto Rui Barbosa. (2017). Índice de efetividade da gestão municipal. Recuperado em 01 mai., 2017, em http://iegm.irbcontas.org.br.

Johnston, J., \& DiNardo, J. (1972). Econometric methods. New York.

Menezes-Filho, N., \& Amaral, L. F. L. E. (2008). A relação entre gastos educacionais e desempenho escolar. São Paulo: IBMEC. Recuperado em 11 mar., 2019, em https://www.researchgate.net/profile/Naercio MenezesFilho/publication/23970136 A Relacao entre Gastos Educacionais e Desempenho Escolar/ links/56efd73808ae52f8ad7f7b2e/A-Relacao-entre-Gastos-Educacionais-e-Desempenho-

Escolar.pdf

Oliveira, A. G. de, \& Pisa, B. J. (2015). IGovP: índice de avaliação da governança pública: Instrumento de planejamento do Estado e de controle social pelo cidadão. RAP - Revista de Administração Pública, 49(5), 1263-1290. Recuperado em 28 abr., 2017, em http://bibliotecadigital.fgv.br/ojs/index.php/rap/article/view/54990/5368 .

Parsons, W. (2006). Innovation in the public sector: Spare tyres and fourth plinths. The Innovation Journal: The Public Sector Innovation Journal, 11(2), 1. Recuperado em 10 nov., 2018, em https://www.innovation.cc/scholarly-style/2006 11_2 1 parsons innovate-public.pdf.

Pereira, O. A., Filho, Tannuri-Pianto, M. E., \& Sousa, M. D. C. S. de. (2010). Medidas de custoeficiência dos serviços subnacionais de segurança pública no Brasil: 2001-2006. Economia Aplicada, 14(3), 313-338. Recuperado em 07 dez., 2018, em http://www.scielo.br/scielo.php?pid=S1413$\underline{80502010000300003 \& \text { script }=\text { sci arttext }}$.

Ranis, G., \& Stewart, F. (2005). Dynamic links between the economy and buman development. UN. Recuperado em 18 ago., 2018, em https://www.un.org/esa/desa/papers/2005/wp8 2005.pdf.

Rezende, A. J., Slomski, V., \& Corrar, L. J. (2005). A gestão pública municipal e a eficiência dos gastos públicos: uma investigação empírica entre as políticas públicas e o índice de desenvolvimento humano (IDH) dos municípios do Estado de São Paulo. Revista Universo Contábil, 1(1), 24-40. Recuperado em 01 jan., 2019, em http://gorila.furb.br/ojs/index.php/universocontabil/article/view/75 .

Scarpin, J. E., \& Slomski, V. (2007). Estudo dos fatores condicionantes do índice de desenvolvimento humano nos municípios do estado do Paraná: Instrumento de controladoria para a tomada de decisões na gestão governamental. Revista de Administração Pública, 41(5), 909-934. $\begin{array}{lllll}\text { Recuperado } & \text { em } & \text { nov., } & 2018, & \text { em }\end{array}$ http://bibliotecadigital.fgv.br/ojs/index.php/rap/article/view/6612 .

Secchi, L. (2009). Modelos organizacionais e reformas da administração pública. RAP - Revista de Administração Pública, 43(2), 347-369. Recuperado em 27 abr., 2017, em http://www.scielo.br/pdf/rap/v43n2/v43n2a04.

Siche, R., Agostinho, F., Ortega, E., \& Romeiro, A. (2007). Índices versus indicadores: precisões conceituais na discussão da sustentabilidade de países. Ambiente \& sociedade. Recuperado em 16 nov., 2018, em http://www.scielo.br/pdf/asoc/v10n2/a09v10n2 .

Silva, A. D. A. P., Ferreira, M. A. M., Braga, M. J., \& Abrantes, L. A. (2012). Eficiência na alocação de recursos públicos destinados à educação, saúde e habitação em municípios mineiros. Revista Contabilidade, Gestão e Governança, 15(1). Recuperado em 18 nov., 2018, em https://cggamg.unb.br/index.php/contabil/article/view/389.

Silva, S. F. D. (2011). Organização de redes regionalizadas e integradas de atenção à saúde: desafios 
do Sistema Único de Saúde (Brasil). Ciência \& Saúde Coletiva, 16(6), 2753-2762. Recuperado em 20 jan., 2019, em https://www.scielosp.org/scielo.php?script=sci arttext\&pid=S1413$\underline{81232011000600014}$

Solà, M., \& Prior, D. (2001). Measuring productivity and quality changes using data envelopment analysis: an application to Catalan hospitals. Financial Accountability \& Management, 17(3), 219-245. Recuperado em 9 dez., 2018, em https://onlinelibrary.wiley.com/doi/abs/10.1111/1468$\underline{0408.00129}$

Souza, F. J. V. D., Melo, M. M. D. D., Silva, M. C. D., \& Araújo, A. O. (2012). Alocação de recursos públicos em educação nos estados brasileiros: Uma análise das relações entre a eficiência dos gastos públicos com educação e o desempenho no IDEB no ano de 2009. Revista UNLABEU, 5(11), 155170. Recuperado em 14 nov., 2018, em https://repositorio.ufrn.br/jspui/bitstream/123456789/19119/1/Aloca $\%$ C3\%A7\% $\%$ C3\%A3oRe cursosPublicos 2012.pdf.

Tan, J.-P., \& Birger, F. (eds). (2008). An African exploration of the East Asian education experience. The World Bank. Recuperado em 5 jul., 2018, em https://elibrary.worldbank.org/doi/pdf/10.1596/978-0-8213-7371-2 .

Tanzi, V. (2004). Measuring efficiency in public expenditure. In Washington, The World Bank. (Paper prepared for the conference on Public Expenditure Efficiency and Growth, October 27). Recuperado em 8 dez., 2018, em https://books.google.com.br/books?hl=ptBR\&lr=\&id $=$ LbiGBDmZfSQC\&oi=fnd\&pg $=$ PA13\&dq=TANZI, + Vito.+ Measuring + efficiency + in + public + expenditure\&ots $=8 y g 71 \mathrm{kqVQO \& sig}=\mathrm{koMvJlE} 1 \mathrm{RNWlJVhDM} 4 \mathrm{e} \quad \mathrm{T} 7 \mathrm{Y} 4 \mathrm{tKA} \#_{\mathrm{v}}=_{\mathrm{O}}$ nepage\&q\&f=false

TCEES - Tribunal de Contas do Estado do Espírito Santo. (2018). Recuperado em 24 nov., 2018, em https://cidades.tce.es.gov.br/\#/IEGM/2016/Manual .

TCESP - Tribunal de Contas de São Paulo. (2017). Recuperado em 01 mai., 2017, em http://iegm.tce.sp.gov.br/help.html .

TCESP. (2014). Indice de efetividade da gestão municipal. São Paulo: Imprensa Oficial do Governo do Estado de São Paulo. Recuperado em 27 abr., 2017 em http://www4.tce.sp.gov.br/sites/tcesp/files/manual-iegm-tcesp 0 0.pdf .

Wooldridge, J.M. (2016). Introdução à econometria: Uma abordagem moderna. São Paulo: Cengage Learning.

Zoghbi, A.C.P., Matos, E.H.C.D., Rocha, F.F., \& Arvate, P.R. (2009). Mensurando o desempenho e a eficiência dos gastos estaduais em educação fundamental e média. Estudos Econômicos, 39(4), 785809. Recuperado em 20 jan., 2019, em http://www.scielo.br/scielo.php?pid=S0101$\underline{41612009000400004 \& \text { script }=\text { sci arttext . }}$ 


\section{APÊNDICE 1}

Questões e memorial de cálculo para os Indicadores de Educação (IEDUC) e saúde (ISAUDE) descritos no Manual do IEGM - TCEES, pgs. 13 a 36.

\section{MEMORIAL DE CÁLCULOS PARA INDICADORES DA EDUCAÇÃO}

\section{\begin{tabular}{l|l} 
Quesitos & Pontuações
\end{tabular}}

\begin{tabular}{|c|c|}
\hline Quesitos & Pontuações \\
\hline \multirow{8}{*}{$\begin{array}{l}\text { 1. A prefeitura municipal realizou ações e medidas para } \\
\text { monitoramento da taxa de abandono das crianças na idade } \\
\text { escolar - Anos Iniciais do Ensino Fundamental }\left(1^{\circ} \text { ao } 5^{\circ} \text { ano)? }\right. \\
\text { Obs.: Ações e medidas documentadas, apenas ligação para } \\
\text { telefone cadastrado do aluno não caracteriza medida para reduzir } \\
\text { a taxa de abandono. }\end{array}$} & $\mathrm{SIM}-05$ \\
\hline & $\begin{array}{l}\text { Quantas crianças abandonaram o Ensino Fundamental } \\
\left(1^{\circ} \text { ao } 5^{\circ} \text { ano por necessidade de trabalho? }\right.\end{array}$ \\
\hline & $\begin{array}{l}\text { Quantas crianças abandonaram o Ensino Fundamental } \\
\left(1^{\circ} \text { ao } 5^{\circ} \text { ano }\right) \text { por dificuldades de aprendizado? }\end{array}$ \\
\hline & $\begin{array}{l}\text { Quantas crianças abandonaram o Ensino Fundamental } \\
\left(1^{\circ} \text { ao } 5^{\circ} \text { ano }\right) \text { por causa de doenças crônicas? }\end{array}$ \\
\hline & $\begin{array}{l}\text { Quantas crianças abandonaram o Ensino Fundamental } \\
\left(1^{\circ} \text { ao } 5^{\circ} \text { ano }\right) \text { por falta de incentivo dos pais? }\end{array}$ \\
\hline & $\begin{array}{l}\text { Quantas crianças abandonaram o Ensino Fundamental } \\
\left(1^{\circ} \text { ao } 5^{\circ} \text { ano por mudança de endereço? }\right.\end{array}$ \\
\hline & $\begin{array}{l}\text { Quantas crianças abandonaram o Ensino Fundamental } \\
\left(1^{\circ} \text { ao } 5^{\circ} \text { ano }\right) \text { por outros motivos? }\end{array}$ \\
\hline & $\mathrm{NÃO}-00$ \\
\hline \multirow{3}{*}{$\begin{array}{l}\text { 2. A prefeitura municipal fez uma pesquisa/estudo para levantar } \\
\text { o número de crianças que necessitavam de creches em 2017? }\end{array}$} & SIM - 05 \\
\hline & Qual o número: \\
\hline & $\mathrm{NÃO}-00$ \\
\hline \multirow{3}{*}{$\begin{array}{l}\text { 3. A prefeitura municipal fez uma pesquisa/estudo para levantar } \\
\text { o número de crianças que necessitavam de pré-escola em 2017? }\end{array}$} & $\mathrm{SIM}-05$ \\
\hline & Qual o número: \\
\hline & $\mathrm{NÃO}-00$ \\
\hline \multirow{3}{*}{$\begin{array}{l}\text { 4. A prefeitura municipal fez uma pesquisa/estudo para levantar } \\
\text { o número de crianças que necessitavam do Ensino Fundamental } \\
\left(1^{\circ} \text { ao } 5^{\circ} \text { ano }\right) \text { escolar em } 2017 \text { ? }\end{array}$} & SIM - 03 \\
\hline & Qual o número: \\
\hline & $\mathrm{NÃO}-00$ \\
\hline \multirow{4}{*}{$\begin{array}{l}\text { 5. A prefeitura aplicou algum programa municipal de avaliação de } \\
\text { rendimento escolar? }\end{array}$} & SIM, avaliação própria - 03 \\
\hline & $\begin{array}{l}\text { SIM, aderiu ao Programa de Avaliação da Educação } \\
\text { Básica do Espírito Santo (PAEBES): - } 02\end{array}$ \\
\hline & $\begin{array}{l}\text { SIM, terceirizada }-01 \\
\text { Qual empresa? }\end{array}$ \\
\hline & NÃO aplicou - 00 \\
\hline \multirow{2}{*}{$\begin{array}{l}\text { 6. A prefeitura municipal utilizou algum indicador de qualidade } \\
\text { para análise da educação do Ensino Fundamental }\left(1^{\circ} \text { ao } 5^{\circ} \text { ano }\right) \text { ? }\end{array}$} & SIM -03 \\
\hline & $\mathrm{NÃO}-00$ \\
\hline \multirow{2}{*}{$\begin{array}{l}\text { 7. Que indicador(es) de qualidade foram utilizados pela prefeitura } \\
\text { municipal para análise da educação do Ensino Fundamental }\left(1^{\circ}\right. \\
\text { ao } 5^{\circ} \text { ano)? }\end{array}$} & IDEB \\
\hline & Outro - Qual? \\
\hline \multirow[t]{2}{*}{ 8. O município possui o Plano Municipal de Educação? } & $\begin{array}{l}\text { SIM - } 05 \\
\text { Informe } \mathrm{n}^{\circ} \text { da lei e data da promulgação: }\end{array}$ \\
\hline & Não - 00 \\
\hline \multirow[t]{2}{*}{$\begin{array}{l}\text { 9. Sobre a infraestrutura de ensino com apoio da Tecnologia, } \\
\text { todas as escolas do Ensino Fundamental }\left(1^{\circ} \text { ao } 5^{\circ} \text { ano }\right) \text { possuem } \\
\text { laboratórios ou sala de informática com computadores para os } \\
\text { alunos da rede escolar municipal? }\end{array}$} & $\begin{array}{l}\text { SIM - } 03 \\
\text { Qual a quantidade de computadores em funcionamento } \\
\text { destinados às aulas de informática em todas as escolas } \\
\text { do município? } \\
\text { Obs. Quantidade de computadores em funcionamento } \\
=\text { total de computadores destinados aos alunos do } \\
\left.\text { Ensino Fundamental ( } 1^{\circ} \text { ao } 5^{\circ} \text { ano }\right) \text { em todas as escolas } \\
\text { do município. }\end{array}$ \\
\hline & $\mathrm{NÃO}-00$ \\
\hline \multirow{2}{*}{$\begin{array}{l}\text { 10. Sobre a infraestrutura das escolas do Ensino Fundamental }\left(1^{\circ}\right. \\
\text { ao } 5^{\circ} \text { ano), informe: }\end{array}$} & $\begin{array}{l}\text { Quantidade de escolas adaptadas para receber crianças } \\
\text { portadoras de necessidades especiais (Rampas e vias de } \\
\text { acesso à escola, adaptação de salas de aula, banheiros e } \\
\text { áreas de esporte e recreação): }\end{array}$ \\
\hline & $\begin{array}{l}\text { Quantidade de escolas que possuem quadra } \\
\text { poliesportiva coberta com dimensões mínimas } \\
(18 \mathrm{~m} \times 30 \mathrm{~m}) \text { : }\end{array}$ \\
\hline $\begin{array}{l}\text { 11. Sobre a infraestrutura e necessidade de reparos nas unidades } \\
\text { de ensino destinadas à creche, pré-escola e Ensino Fundamental } \\
\left(1^{\circ} \text { ao } 5^{\circ} \text { ano }\right) \text { do município no ano de } 2017 \text {, responda: }\end{array}$ & $\begin{array}{l}\text { Quantas unidades de ensino necessitavam de reparos } \\
\text { (conserto de janelas, rachaduras, infiltrações, fiação } \\
\text { elétrica, substituição de azulejos danificados, etc) em }\end{array}$ \\
\hline
\end{tabular}




\begin{tabular}{|c|c|}
\hline & $\begin{array}{l}\text { dezembro de } 2017 \text { ? <Quantidade }>\text { ou Não possui } \\
\text { registro }\end{array}$ \\
\hline & $\begin{array}{l}\text { Quantas unidades de ensino tiveram seu funcionamento } \\
\text { interrompido ou foram abandonadas por problemas de } \\
\text { infraestrutura? < Quantidade }>\text { ou Não possui } \\
\text { registro }\end{array}$ \\
\hline $\begin{array}{l}\text { 12. Número de crianças de } 4 \text { a } 5 \text { anos de idade não matriculadas } \\
\text { na pré-escola em 2017: }\end{array}$ & $<$ Quantidade $>$ ou Não possui registro \\
\hline \multirow{3}{*}{ 13. Qual o piso salarial municipal dos professores? } & Creche: \\
\hline & Pré-escola: \\
\hline & Ensino Fundamental $\left(1^{\circ}\right.$ ao $5^{\circ}$ ano $)$ : \\
\hline \multirow{2}{*}{$\begin{array}{l}\text { 14. O município divulga e cumpre o cardápio pré-estabelecido } \\
\text { pela nutricionista? }\end{array}$} & $\mathrm{SIM}-03$ \\
\hline & $\mathrm{NÃO}-00$ \\
\hline \multirow{2}{*}{$\begin{array}{l}\text { 15. Existe um estudo anual do traçado e tempo de viagem das } \\
\text { rotas do transporte escolar? }\end{array}$} & $\begin{array}{l}\text { SIM } \\
\text { Qual a média de tempo (em minutos)? }\end{array}$ \\
\hline & $\mathrm{NÃO}$ \\
\hline $\begin{array}{l}\text { 16. Qual a idade média da frota escolar, em anos? } \\
\text { Obs. Idade média = [(Ano de } 2017) \text { - (Ano de fabricação de cada } \\
\text { veículo)]/(número total de veículos da frota escolar) }\end{array}$ & \\
\hline \multirow{3}{*}{ 17. Como é feita a preparação da merenda no município? } & Cozinha piloto própria \\
\hline & Nas escolas (que possuem merendeiras próprias) \\
\hline & $\begin{array}{l}\text { Terceirizada } \\
\text { Qual o custo unitário médio do almoço? }\end{array}$ \\
\hline \multirow{3}{*}{$\begin{array}{l}\text { 18. Existe um controle por meio de relatórios elaborado pela } \\
\text { nutricionista que permita atestar as condições físicas/estruturais } \\
\text { da cozinha, higienização e acondicionamento dos alimentos e } \\
\text { acompanhamento/aceitação do cardápio proposto na rede escolar } \\
\text { municipal? }\end{array}$} & SIM, semanalmente -02 \\
\hline & SIM, mensalmente -01 \\
\hline & $\mathrm{NÃO}-00$ \\
\hline \multirow{2}{*}{$\begin{array}{l}\text { 19. Todos os professores da Educação Básica possuem formação } \\
\text { específica de nível superior, obtida em curso de licenciatura na } \\
\text { área de conhecimento em que atuam, conforme instituído no art. } \\
62 \text { da Lei } N^{\circ} 9.394 \text {, de } 20 \text { de dezembro DE } 1996 \text { ? }\end{array}$} & SIM - 05 \\
\hline & $\begin{array}{l}\text { NÃO - } 00 \\
\text { Qual o percentual de professores que possuem? }\end{array}$ \\
\hline \multirow{2}{*}{$\begin{array}{l}\text { 20. O Conselho de Alimentação Escolar elaborou atas que } \\
\text { permitam atestar as condições físicas/estruturais da cozinha, } \\
\text { higienização e acondicionamento dos alimentos, bem como } \\
\text { avaliar o cardápio e sua aceitação pelos alunos, considerando itens } \\
\text { como quantidade e qualidade, variedade, respeito aos hábitos } \\
\text { locais e regionais, adequação ao horário, conservação e manuseio } \\
\text { dos alimentos e condições higiênicas dos locais de preparo e } \\
\text { serviço? }\end{array}$} & $\begin{array}{l}\text { SIM - } 04 \\
\text { Qual a quantidade de visitas que o CAE realizou nas } \\
\text { escolas do Ensino Fundamental }\left(1^{\circ} \text { ao } 5^{\circ} \text { ano }\right) \text { no ano } \\
\text { de } 2017 \text { ? }\end{array}$ \\
\hline & $\mathrm{NÃO}-00$ \\
\hline \multirow{4}{*}{$\begin{array}{l}\text { 21. O município utilizou algum programa específico que } \\
\text { desenvolveu as competências de leitura e escrita de seus alunos na } \\
\text { rede municipal? }\end{array}$} & $\begin{array}{l}\text { SIM }-04 \\
\text { Qual? }\end{array}$ \\
\hline & Percentual de cobertura $-1^{\circ}$ ano: \\
\hline & Percentual de cobertura - $2^{\circ}$ ano: \\
\hline & Percentual de cobertura - $3^{\circ}$ ano: \\
\hline \multirow{3}{*}{ Obs.: Não considerar treinamentos voltados para os professores. } & Percentual de cobertura $-4^{\circ}$ ano: \\
\hline & Percentual de cobertura - $5^{\circ}$ ano: \\
\hline & $\mathrm{NA} \mathrm{AO}-00$ \\
\hline 22. Qual o total de turmas para creche? & <Quantidade > ou Não possui registro \\
\hline 23. Qual o total de turmas para pré-escola? & $<$ Quantidade $>$ ou Não possui registro \\
\hline $\begin{array}{l}\text { 24. Qual o total de turmas para o Ensino Fundamental }\left(1^{\circ} \text { ao } 5^{\circ}\right. \\
\text { ano)? }\end{array}$ & $<$ Quantidade $>$ ou Não possui registro \\
\hline $\begin{array}{l}\text { 25. Qual a quantidade de alunos que terminaram o último ano do } \\
\text { Ensino Fundamental }\left(1^{\circ} \text { ao } 5^{\circ} \text { ano }\right) \text { em } 2017 \text { ? }\end{array}$ & $<$ Quantidade $>$ ou Não possui registro \\
\hline $\begin{array}{l}\text { 26. Qual a quantidade de alunos matriculados no } 5^{\circ} \text { ano do } \\
\text { Ensino Fundamental }\left(1^{\circ} \text { ao } 5^{\circ} \text { ano }\right) \text { em } 2017 \text { que tiveram } \\
\text { aproveitamento para o } 6^{\circ} \text { ano do Ensino Fundamental em } 2018 \text { ? }\end{array}$ & $<$ Quantidade $>$ ou Não possui registro \\
\hline \multirow{6}{*}{$\begin{array}{l}\text { 27. Informe a quantidade total (dias) de ausência dos professores } \\
\text { por faltas (incluindo os afastamentos legais) para o Ensino } \\
\text { Fundamental }\left(1^{\circ} \text { ao } 5^{\circ} \text { ano): <Quantidade> ou Não possui }\right. \\
\text { registro } \\
\text { Obs. Todos os dias de ausência de professor do Ensino } \\
\text { Fundamental ( } 1^{\circ} \text { ao } 5^{\circ} \text { ano) no ano de } 2017 \text { (justificadas ou } \\
\text { injustificadas) }\end{array}$} & Faltas injustificadas: \\
\hline & Faltas justificadas: \\
\hline & Licença médica: \\
\hline & Licença maternidade/paternidade: \\
\hline & Abonos: \\
\hline & $\begin{array}{l}\text { Outros: (inclusive ausências pontuais amparadas por } \\
\text { lei). }\end{array}$ \\
\hline
\end{tabular}




\begin{tabular}{|c|c|}
\hline $\begin{array}{l}\text { 28. Qual a quantidade de unidades públicas municipais de ensino } \\
\text { (estabelecimentos físicos) destinadas à creche, pré-escola e Ensino } \\
\text { Fundamental }\left(1^{\circ} \text { ao } 5^{\circ} \text { ano }\right) \text { em } 2017 \text { ? }\end{array}$ & $<$ Quantidade $>$ ou Não possui registro \\
\hline \multirow{3}{*}{$\begin{array}{l}\text { 29. Quantas vagas foram disponibilizadas no ano de } 2017 \text { para } \\
\text { período integral? }\end{array}$} & Creche: $<$ Quantidade $>$ ou Não possui registro \\
\hline & Pré-escola: <Quantidade> ou Não possui registro \\
\hline & $\begin{array}{l}\text { Ensino Fundamental }\left(1^{\circ} \text { ao } 5^{\circ} \text { ano }\right):<\text { Quantidade }>\text { ou } \\
\text { Não possui registro }\end{array}$ \\
\hline \multirow{2}{*}{$\begin{array}{l}\text { 30. Existe Conselho Municipal de Educação estruturado e atuante } \\
\text { com a composição de membros completa e de acordo com a } \\
\text { legislação? }\end{array}$} & $\mathrm{SIM}-04$ \\
\hline & $\mathrm{NÃO}-00$ \\
\hline \multirow{3}{*}{$\begin{array}{l}\text { 31. Quanto foi aplicado de recursos municipais, em reais, na } \\
\text { capacitação e avaliação do corpo docente municipal em 2017? }\end{array}$} & Creche: <Quantidade> ou Não possui registro \\
\hline & Pré-escola: <Quantidade> ou Não possui registro \\
\hline & $\begin{array}{l}\text { Ensino Fundamental }\left(1^{\circ} \text { ao } 5^{\circ} \text { ano }\right):<\text { Quantidade }>\text { ou } \\
\text { Não possui registro }\end{array}$ \\
\hline \multirow{3}{*}{$\begin{array}{l}\text { 32. O município utiliza material didático elaborado por empresa } \\
\text { terceirizada (livros e/ou apostilas de sistemas de ensino)? }\end{array}$} & SIM: \\
\hline & Informe a CNPJ e Razão social da(s) empresa(s) \\
\hline & NÃO \\
\hline \multirow{6}{*}{$\begin{array}{l}\text { 33. Qual a principal razão para pagamento de horas extras para os } \\
\text { professores? }\end{array}$} & Não existe pagamento de horas extras \\
\hline & Realização de feiras e eventos aos finais de semana \\
\hline & Absenteísmo de professores \\
\hline & Cobertura de férias e licenças \\
\hline & Não possui equipe completa \\
\hline & Outro - qual? \\
\hline \multirow{2}{*}{$\begin{array}{l}\text { 34. O município possui levantamento da distorção idade/série no } \\
\text { Ensino Fundamental }\left(1^{\circ} \text { ao } 5^{\circ} \text { ano)? }\right.\end{array}$} & SIM \\
\hline & NÃO \\
\hline \multicolumn{2}{|l|}{ 35. Qual a data de início do ano letivo de 2017? } \\
\hline $\begin{array}{l}\text { 36. Quanto às bibliotecas e salas de leitura na rede municipal, } \\
\text { responda: }\end{array}$ & $\begin{array}{l}\text { Quantas escolas da rede municipal possuem bibliotecas? } \\
\text { Obs. A definição de biblioteca, segundo os critérios do } \\
\text { FUNDEB, exige a presença de um Bibliotecário. }\end{array}$ \\
\hline $\begin{array}{l}\text { Obs.: Caso a escola possua biblioteca e também sala de leitura, } \\
\text { esta deve ser contada apenas uma vez, no valor referente a } \\
\text { escolas com biblioteca. }\end{array}$ & \\
\hline $\begin{array}{l}\text { Metodologia de Cálculo: Pontuação obtida através do cálculo do } \\
\text { desvio padrão da razão entre o } \mathbf{n}^{\mathbf{0}} \text { de escolas com biblioteca ou } \\
\text { sala de leitura e o } \mathbf{n}^{\mathbf{0}} \text { de escolas no município. } \\
\text { Para Outliers: } 03 \text { pontos } \\
\text { Para municípios dentro do intervalo de dispersão: } 02 \text { pontos } \\
\text { Para pontos de atenção: } 00 \text { ponto }\end{array}$ & $\begin{array}{l}\text { Quantas escolas da rede municipal possuem sala de } \\
\text { leitura? }\end{array}$ \\
\hline \multirow[t]{2}{*}{$\begin{array}{l}\text { 37. Houve entrega do material didático (livros, apostilas, etc.) aos } \\
\text { alunos na rede municipal? }\end{array}$} & $\begin{array}{l}\text { SIM } \\
\text { Data da entrega: } \\
\text { - se data }<=\text { início das aulas }=04 \text { pontos } \\
\text { - se data }<\text { início das aulas }+15 \text { dias }=02 \text { pontos } \\
\text { - se data }>=\text { início das aulas }+15 \text { dias }=00 \text { ponto }\end{array}$ \\
\hline & $\mathrm{NÃO}-00$ ponto \\
\hline \multirow[t]{2}{*}{ 38. Houve entrega do uniforme escolar à rede municipal? } & $\begin{array}{l}\text { SIM } \\
\text { Data da entrega: } \\
\text { - se data }<=\text { início das aulas }=04 \text { pontos } \\
\text { - se data }<\text { início das aulas }+30 \text { dias }=02 \text { pontos } \\
\text { - se data }>=\text { início das aulas }+30 \text { dias }=00 \text { ponto }\end{array}$ \\
\hline & $\mathrm{NÃO}-00$ ponto \\
\hline \multirow[t]{2}{*}{$\begin{array}{l}\text { 39. Existe um programa de inibição ao absenteísmo de } \\
\text { professores em sala de aula (incluindo os afastamentos legais)? }\end{array}$} & $\begin{array}{l}\text { SIM, com benefício financeiro; com processo de perícia } \\
\text { médica municipal; com programas de prevenção à saúde } \\
\text { do professor }-05\end{array}$ \\
\hline & NÃ̃: 00 \\
\hline $\begin{array}{l}\text { 40. A Prefeitura/Secretaria da Educação Municipal possui Plano } \\
\text { de Cargos e Salários para seus professores? }\end{array}$ & $\begin{array}{l}\text { SIM: } 00 \text { ponto } \\
\text { Qual o número da lei? }\end{array}$ \\
\hline
\end{tabular}




\begin{tabular}{|c|c|}
\hline & NÃO: -1 (Menos um ponto) \\
\hline \multirow{3}{*}{$\begin{array}{l}\text { 41. Informe o total de horas de treinamento e capacitação } \\
\text { oferecidos pelo município destinados a professores no exercício } \\
\text { de 2017: }\end{array}$} & Creche: $<$ Quantidade $>$ ou Não possui registro \\
\hline & Pré-escola: <Quantidade> ou Não possui registro \\
\hline & $\begin{array}{l}\text { Ensino Fundamental }\left(1^{\circ} \text { ao } 5^{\circ} \text { ano }\right):<\text { Quantidade }>\text { ou } \\
\text { Não possui registro }\end{array}$ \\
\hline \multirow[t]{2}{*}{ 42. Houve entrega do Kit escolar à rede municipal? } & SIM \\
\hline & Data da entrega: \\
\hline \multirow{3}{*}{$\begin{array}{l}\text { EXEMPLO de composição de um kit escolar: } \\
\text { - Caderno "Brochurão" - } 4 \text { unidades ( } 96 \text { folhas cada) } \\
\text { - Caderno de Desenho }-1 \text { unidade ( } 96 \text { folhas cada) } \\
\text { - Régua } 30 \mathrm{~cm}-1 \text { unidade } \\
\text { - Lápis de cor grande ( } 12 \text { cores) - } 2 \text { caixa } \\
\text { - Lápis grafite }-4 \text { unidades } \\
\text { - Lápis grafite de resina termoplástica - } 4 \text { unidades } \\
\text { - Caneta esferográfica azul - } 4 \text { unidades } \\
\text { - Apontador com depósito }-6 \text { unidades } \\
\text { - Borracha branca - } 3 \text { unidades } \\
\text { - Tubo de cola branca }-3 \text { unidades } \\
\text { - Giz de cera ( } 12 \text { cores grande })-1 \text { caixa } \\
\text { - Guache ( } 12 \text { cores }) \text { - } 1 \text { caixa }\end{array}$} & - se data $<=$ início das aulas $=04$ pontos \\
\hline & $\begin{array}{l}\text { - se data }<\text { início das aulas }+15 \text { dias }=02 \text { pontos } \\
\text { - se data }>=\text { início das aulas }+15 \text { dias }=00 \text { ponto }\end{array}$ \\
\hline & 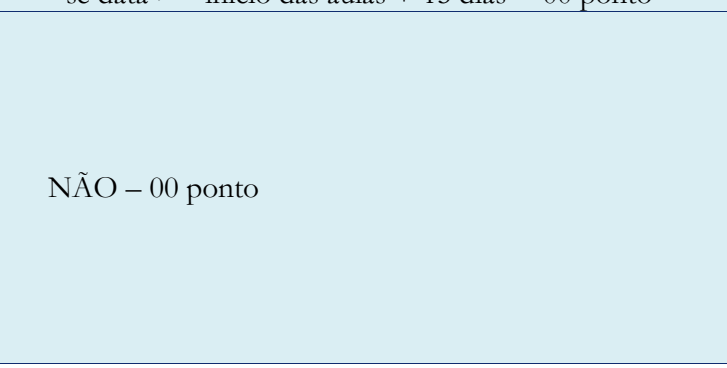 \\
\hline \multirow{4}{*}{$\begin{array}{l}\text { 43. Quantas reuniões foram realizadas pelo Conselho Municipal } \\
\text { de Educação no último exercício? } \\
\text { (Não considerar reuniões de eleição/exclusão de membros, } \\
\text { aprovação de orçamento ou outro assunto não relacionado à } \\
\text { natureza do Conselho) }\end{array}$} & 8 ou mais reuniões -04 pontos \\
\hline & 6 a 7 reuniões -02 pontos \\
\hline & 4 a 5 reuniões -01 ponto \\
\hline & 0 a 3 reuniões -00 ponto \\
\hline \multirow{2}{*}{$\begin{array}{l}\text { 44. Quanto ao número de profissionais da educação não docentes } \\
\text { (Ex: monitor, pedagoga, psicóloga, secretária, etc) atuantes no } \\
\text { Ensino Fundamental }\left(1^{\circ} \text { ao } 5^{\circ} \text { ano), informe: }\right.\end{array}$} & $\begin{array}{l}\text { Número de profissionais ocupantes de cargos de } \\
\text { provimento efetivo: }<\text { Quantidade }>\text { ou Não possui } \\
\text { registro }\end{array}$ \\
\hline & $\begin{array}{l}\text { Número de profissionais temporários: <Quantidade> } \\
\text { ou Não possui registro }\end{array}$ \\
\hline \multirow{2}{*}{$\begin{array}{l}\text { 45. Sobre o Fundo de Manutenção e Desenvolvimento da } \\
\text { Educação Básica e de Valorização dos Profissionais da Educação } \\
\text { - FUNDEB, informe, com base na Lei n }{ }^{\circ} 11.494 \text {, de } 20 \text { de junho } \\
\text { de 2007: }\end{array}$} & Percentual aplicado dos recursos oriundos do fundo \\
\hline & $\begin{array}{l}\text { Percentual dos recursos oriundos do fundo aplicado no } \\
\text { Magistério. }\end{array}$ \\
\hline \multirow{2}{*}{$\begin{array}{l}\text { 46. Com base no art. } 212 \text { da Constituição da República Federativa } \\
\text { do Brasil, informe o percentual da receita resultante de impostos, } \\
\text { compreendida a proveniente de transferências, aplicado na } \\
\text { manutenção e desenvolvimento do ensino. } \\
\text { Obs.: informe apenas o percentual de } 0 \% \text { a } 100 \% \text {. Apenas } \\
\text { números, vírgula e duas casas decimais. }\end{array}$} & $\begin{array}{l}\text { Atingiu o percentual mínimo. } \\
\text { SIM }-14\end{array}$ \\
\hline & $\begin{array}{l}\text { Não atingiu o percentual mínimo. } \\
\text { NÃO - } 00\end{array}$ \\
\hline \multicolumn{2}{|l|}{ 47. Qual a quantidade de matrículas realizadas em creche? } \\
\hline \multicolumn{2}{|l|}{ 48. Qual a quantidade de matrículas realizadas em pré-escola? } \\
\hline \multicolumn{2}{|l|}{$\begin{array}{l}\text { 49. Qual a quantidade de matrículas realizadas no Ensino } \\
\text { Fundamental }\left(1^{\circ} \text { ao } 5^{\circ} \text { ano }\right) \text { ? }\end{array}$} \\
\hline \multicolumn{2}{|l|}{ 50. Qual a quantidade de professores efetivos destinados à creche? } \\
\hline \multicolumn{2}{|l|}{$\begin{array}{l}\text { 51. Qual a quantidade de professores temporários destinados à } \\
\text { creche? }\end{array}$} \\
\hline \multicolumn{2}{|l|}{$\begin{array}{l}\text { 52. Qual a quantidade de professores efetivos destinados à pré- } \\
\text { escola? }\end{array}$} \\
\hline \multicolumn{2}{|l|}{$\begin{array}{l}\text { 53. Qual a quantidade de professores temporários destinados à pré- } \\
\text { escola? }\end{array}$} \\
\hline \multicolumn{2}{|l|}{$\begin{array}{l}\text { 54. Qual a quantidade de professores efetivos destinados ao Ensino } \\
\text { Fundamental }\left(1^{\circ} \text { ao } 5^{\circ} \text { ano }\right) \text { ? }\end{array}$} \\
\hline \multicolumn{2}{|l|}{$\begin{array}{l}\text { 55. Qual a quantidade de professores temporários destinados ao } \\
\text { Ensino Fundamental }\left(1^{\circ} \text { ao } 5^{\circ} \text { ano)? }\right.\end{array}$} \\
\hline \multirow{3}{*}{$\begin{array}{l}\text { 56. Informe a porcentagem de professores efetivos com pós- } \\
\text { graduação: }\end{array}$} & Creche: \\
\hline & Pré-escola: \\
\hline & Ensino Fundamental $\left(1^{\circ}\right.$ ao $5^{\circ}$ ano $)$ : \\
\hline \multirow{3}{*}{$\begin{array}{l}\text { 57. Quantos estabelecimentos municipais de ensino destinados à } \\
\text { creche, pré-escola e Ensino Fundamental }\left(1^{\circ} \text { ao } 5^{\circ} \text { ano }\right) \text { estavam } \\
\text { funcionando durante o exercício de } 2017 \text { ? } \\
\text { Ex: Caso haja escola mista de pré-escola e Ensino Fundamental }\left(1^{\circ}\right. \\
\text { ao } 5^{\circ} \text { ano), considerar } 1 \text { estabelecimento em pré-escola e } 1 \text { em Ensino } \\
\text { Fundamental }\left(1^{\circ} \text { ao } 5^{\circ} \text { ano }\right)\end{array}$} & Creche: \\
\hline & Pré-escola: \\
\hline & Ensino Fundamental $\left(1^{\circ}\right.$ ao $5^{\circ}$ ano): \\
\hline \multirow{3}{*}{$\begin{array}{l}\text { 58. Quantos estabelecimentos de ensino estavam funcionando em } \\
\text { período integral durante o exercício de } 2017 \text { ? } \\
\text { Ex: Caso haja escola mista de pré-escola e Ensino Fundamental }\left(1^{\circ}\right.\end{array}$} & Creche: \\
\hline & Pré-escola: \\
\hline & Ensino Fundamental $\left(1^{\circ}\right.$ ao $5^{\circ}$ ano): \\
\hline
\end{tabular}


ao $5^{\circ}$ ano), considerar 1 estabelecimento em pré-escola e 1 em Ensino Fundamental $\left(1^{\circ}\right.$ ao $5^{\circ}$ ano $)$

59. Qual a quantidade total de professores/profissionais de educação em sala de aula para atendimento constante e direto dos alunos da rede municipal?
Creche:

Pré-escola:

$1^{\circ}$ ano - Ensino Fundamental:

$2^{\circ}$ ano - Ensino Fundamental:

$3^{\circ}$ ano - Ensino Fundamental:

$4^{\circ}$ ano - Ensino Fundamental:

$5^{\circ}$ ano - Ensino Fundamental:

\section{Totalização}

Pontos máximos: 100

Pontos mínimos: 000
Peso da Dimensão Educação Pública

i-EDUC: $20 / 100-0,20(20 \%)$

Fórmula matemática aplicada após análise fatorial

i-EDUC $=($ Somatório dos indicadores $) / 100$ 


\section{MEMORIAL DE CÁLCULOS PARA INDICADORES DA SAÚDE}

\section{Quesitos}

1. O município possui informação sistematizada sobre os gargalos/demanda reprimida de atendimento ambulatorial/hospitalar de média e alta complexidade de referência para a Atenção Básica?

2. O município disponibiliza consultas médicas à distância utilizando instrumentos tecnológicos (telefone, Internet, etc.)? Obs. Não considerar marcação de consulta nem orientação médica emergencial

3. O Município divulga nas UBS em local acessível ao público a escala atualizada de serviço dos profissionais de saúde contendo o nome e o horário de entrada e saída destes servidores?

4. Os locais de atendimento médico-hospitalar e as unidades de saúde de atenção básica municipais estão regulares perante o Corpo de Bombeiros)?

5. Os locais municipais de atendimento médico-hospitalar e UBSs possuem alvará de funcionamento da Vigilância Sanitária, ou documentação comprovando que cumprem as exigências pertinentes às instalações, aos equipamentos e à aparelhagem adequada e à assistência e responsabilidade técnicas, aferidas por meio de fiscalização realizada pelo órgão sanitário local? 6. O município possui gestão de estoque dos insumos (Ex.: luvas, capotes, gorros, máscaras e seringas) para operacionalização da sua atenção básica: estoque mínimo, variação do estoque?

7. O atendimento nas unidades municipais que prestam assistência em saúde já foi interrompido ou descontinuado por falta de insumos?

8. O município possui o componente municipal do Sistema Nacional de Auditoria estruturado?

9. A prefeitura realizou campanha anual ou incentivo em grupos de gestantes para a promoção do aleitamento materno? Obs.: A orientação passada durante as consultas não configura campanha anual ou incentivo.

10. Qual o percentual de cobertura da população-alvo, em média, nas campanhas de vacinação? <Quantidade> ou Não possui registro

11. O cadastro e o acompanhamento específicos para pacientes portadores de hipertensão estão atualizados?

12. O cadastro e o acompanhamento específicos para pacientes portadores de Diabetes Melittus está atualizado?

13. Os médicos cumprem integralmente sua jornada de trabalho?

14. As unidades básicas de saúde no município possuem condições técnicas para realização de tratamento supervisionado para os casos de tuberculose?

Sobre a incidência de tuberculose no município no ano de 2017, informe:

16. Qual o percentual de unidades com sala de vacinação com funcionamento em 05 dias da semana?

17. Os médicos da UBS possuem sistema de controle de ponto eletrônico? (Ex.: mecânico; biométrico; digital; etc)
Pontuações

SIM -12

Qual é o tempo médio de espera (em dias) até a primeira consulta?

$\mathrm{NA} \mathrm{AO}-00$

$\mathrm{SIM}-00$

$\mathrm{NÃO}-05$

SIM -05

$\mathrm{NA} \mathrm{O}-00$

SIM, todos possuem - 08

SIM, a maior parte possui - 05

SIM, a menor parte possui -03

$\mathrm{N} \tilde{\mathrm{AO}}-00$

SIM, todos possuem - 10

SIM, a maior parte possui - 07

SIM, a menor parte possui -04

$\mathrm{NA} \mathrm{O}-00$

SIM (sistematizada) -05

SIM (manual) -03

$\mathrm{NÃO}-00$

SIM

$\mathrm{NÃO}$

SIM

$\mathrm{NÃO}$

$\mathrm{SIM}-03$

$\mathrm{NA} \mathrm{O}-00$

Referente ao calendário de vacinação do $1^{\circ}$ ano de vida: Referente ao calendário de vacinação do $2^{\circ}$ ano de vida: Referente ao calendário da população adulta:

SIM

$\mathrm{NÃO}$

SIM

$\mathrm{NÃO}$

$\mathrm{SIM}-07$

Permanece apenas nas consultas agendadas -03

$\mathrm{N} \tilde{\mathrm{AO}}-00$

SIM, todas possuem -05

SIM, a maior parte das UBS possui - 03

SIM, a menor parte das UBS possui - 01

$\mathrm{NÃO}-00$

Total de casos novos tuberculose (todos os tipos)

diagnosticados no ano:

Não houve casos da doença no município

Não possui registro

Total de casos novos de tuberculose (todos os tipos) no ano

com exame anti-HIV realizado:

Não houve casos da doença no município

Não possui registro

Taxa de cura de tuberculose no município (todos os tipos):

Não houve casos da doença no município

Não possui registro

Total de casos novos tuberculose pulmonar bacilífera

diagnosticados no ano:

Não houve casos da doença no município

Não possui registro

Taxa de cura de tuberculose pulmonar bacilífera no município (todos os tipos):

Não houve casos da doença no município

Não possui registro

0\%: 00 ponto

$01 \%-49,99 \%$ : 01 ponto

$50 \%-74,99 \%: 03$ pontos

$75 \%$ ou mais: 05 pontos

$\mathrm{SIM}-03$

$\mathrm{NA} \mathrm{O}-00$ 
Obs. Livro ponto não é controle eletrônico.

18. O município disponibiliza serviço de agendamento de consulta médica nas

UBSs por meio de telefone, VOIP, Internet, toten, etc.?

19. Foi realizada ação para a promoção da saúde bucal nas escolas?

Obs.: Palestras e escovação não configuram consulta.

20. Qual o número de Equipes de Saúde da Família (ESF) no município?

21. Sobre a presença de médicos nas ESF, informe:

SIM -03

$\mathrm{NÃO}-00$

SIM, com consulta odontológica das crianças - 03

SIM, somente com divulgação - 01

$\mathrm{NÃO}-00$

Todas as equipes contam com médicos -03

A maior parte das equipes conta com médicos - 02

A menor parte das equipes conta com médicos - 01

As equipes não contam com nenhum médico - 00

Recursos humanos próprios

Convênio

\begin{tabular}{l|l} 
22. Qual a forma de gestão municipal no Programa Saúde da Família? & Contrato de gestão \\
\hline
\end{tabular}

Termo de parceria

Outro

Qual:

23. Qual o número de agentes comunitários de saúde no município?

Número de nascidos vivos de mães residentes no município: $<$ NÚMERO $>$ Ou NÃO POSSUI REGISTRO

24. Quanto ao número de nascidos vivos no município no ano de 2017, informe:

umero total de nascidos vivos de mães residentes no município que realizaram 7 ou mais consultas de pré-natal na rede municipal de saúde: <NÚMERO> ou NÃO POSSUI

REGISTRO

25. Qual a cobertura da terceira dose da vacina pentavalente aplicada no total de crianças menores de 1 ano de idade?

26. Qual o número de consultas médicas básicas realizadas nas UBSs do município no último ano?

$<$ PERCENTUAL $>$

NÃO POSSUI REGISTRO

$<$ NÚMERO $>$

NÃO POSSUI REGISTRO

A Prefeitura tem SAMU

27. Sobre atendimento de urgências, responda:

(É possível selecionar várias opções)

A Prefeitura mantém apenas convênio de atendimento préhospitalar com o Corpo de Bombeiros

A Prefeitura possui outro sistema de atendimento a urgências Qual:

Descreva sucintamente:

28. Qual o intervalo de tempo médio de espera entre a marcação de consulta em especialidade médica e seu efetivo atendimento na UBS (em dias)?

$<$ TEMPO EM DIAS $>$

29. Existe Conselho Municipal de Saúde estruturado e atuante com a composição de membros completa e de acordo com a legislação?

30. Quantas reuniões foram realizadas pelo Conselho Municipal de Saúde em 2017?

Obs.: Não considerar reuniões de eleição/exclusão de membros, aprovação de orçamento ou outro assunto não relacionado à natureza do Conselho)

31. Qual a principal razão para pagamento de horas extras para os médicos?

NAO POSSUI REGISTRO

\section{SIM -05}

$\mathrm{NÃO}-00$

8 ou mais reuniões -05 pontos

6 a 7 reuniões -03 pontos

4 a 5 reuniões -01 ponto

0 a 3 reuniões -00 ponto

Não existe pagamento de horas extras

Realização de campanhas e eventos aos finais de semana

Absenteísmo

Cobertura de férias e licenças

Não possui equipe completa

Outros (Quais?)

\section{Qual a quantidade total de horas extras em 2017 para médicos?}

33. Sobre a dengue no município em 2017, informe:

Número de casos diagnosticados:

Número de óbitos:

Número total de imóveis da área urbana do município:

34. O município possui Plano Municipal da Saúde com período correspondente ao PPA vigente?

35. Qual a quantidade de médicos ativos do município em 2017?

Carga horária: 20h; $30 \mathrm{~h}$ ou $40 \mathrm{~h}$ semanais.

36. Qual o intervalo de tempo médio de espera, em dias, entre a marcação de exames complementares laboratoriais (bioquímicos, de imagem, patológicos, coleta de materiais e etc.) solicitados na consulta na UBS e sua efetiva realização?

37. O município possui Ouvidoria da Saúde implantada?

SIM

$\mathrm{NÃO}$

Informe, para cada mês do ano de 2017, a quantidade de médicos ativos por carga horária cumprida: $20 \mathrm{~h}, 30 \mathrm{~h}$ e $40 \mathrm{~h}$ semanais.

SIM

Qual a quantidade de atendimentos realizados no último ano? NÃO

SIM

NÃO

38. A Ouvidoria de Saúde possui relatórios de atendimentos?

39. O Fundo Municipal movimenta todos os recursos da Saúde mediante contas bancárias próprias?

SIM

NÃO

SIM

40. O município tem implantado o Sistema Nacional de Gestão da Assistência Farmacêutica (Hórus)?

Quantos estabelecimentos farmacêuticos (farmácias e centrai de abastecimento farmacêutico) da Atenção Básica existem no Município? 


\section{Mayte Cardoso Aguiar, Aridelmo Teixeira e Aziz Beiruth}

41. Sobre as internações clínicas ocorridas no município em 2017, informe:

42. Sobre as internações clínicas de pacientes residentes no município ocorridas em 2017, informe:
Quantos destes estabelecimentos farmacêuticos têm implantado o sistema Hórus ou envia o conjunto de dados por meio do serviço WebService?

NÃO

Quantidade de internações clínicas ocorridas no município:

Quantidade de internações por causas sensíveis à Atenção

Básica:

Quantidade de internações clínicas ocorridas no município

(Considere apenas as internações de pessoas residentes no município):

Quantidade de internações por cada uma das condições sensíveis à atenção básica abaixo: (Considere apenas as internações de pessoas residentes no município):

Doenças evitáveis por imunização e outras DIP: Anemia:

Pneumonias bacterianas:

Asma:

Bronquites:

Hipertensão:

Insuficiência cardíaca:

Diabetes mellitus:

Epilepsias:

Infecção no rim e trato urinário:

Doença inflamatória nos órgãos pélvicos femininos:

Outras doenças sensíveis à atenção básica:

Para responder às questões 43 e 44, considere a seguinte lista CID-10 das Condições Sensíveis à Atenção Básica:

Condições Sensíveis

Lista dos CID-10

(todos do intervalo especificado)

A15.0-A19.9, A33.0-A37.9; A50.0-A53.9, A95.0-A95.9, B05.0B06.9, B16.0-B16.9, B26.0-B26.9, B50.0-B54.9, B77.0-B77.9, G00.0, I00-I02.9

D50.0-D50.9

J13, J14, J15.3-J15.4, J15.8-J15.9, J18.1

2. Anemia:

3. Pneumonias bacterianas:

Condições Sensíveis

4. Asma:

5. Bronquites:

6. Hipertensão:

7. Insuficiência cardíaca:

8. Diabetes mellitus:

9. Epilepsias:

10. Infecção no rim e trato urinário:

11. Doença inflamatória nos órgãos pélvicos femininos:

Lista dos CID-10

(todos do intervalo especificado)

J45.0-J45.9

$\mathrm{J} 20.0-\mathrm{J} 21.9, \mathrm{~J} 40-\mathrm{J} 42$

I10, I11.0-I11.9

I50.0-I50.9

E10.0-E14.9

G40.0-G40.9

N30.0-N30.9, N34.0-N34.3, N39.0

N70.0-N73.9, N75.0-N76.8

Considere como Outras doenças sensíveis à atenção básica as seguintes:

Outras Condições Sensíveis

12. Gastroenterites infecciosas e complicações:

13. Deficiências nutricionais

14. Infecções de ouvido, nariz e garganta

15. Angina

16. Infecção da pele e tecido subcutâneo

17. Síndrome da Rubéola Congênita

Lista dos CID-10

(todos do intervalo especificado)

A00.0-A09.9; E86.0-E86.9

E40-E46.9, E50.0-E64.9

H66.0-H66.9, J00, J01.0-J03.9,

J06.0-J06.9, J31.0-J31.9

I20.0-I20.9

A46, L01.0-L04.9, L08.0-L08.9

P35.0

Observação: o rol de causas das internações sensíveis à Atenção Básica acima não é idêntico à Lista Brasileira de Internações por Condições Sensíveis à Atenção Primária, publicada pela Portaria MS/ SAS n 221, de 17 de abril de 2008, embora seja baseado nesta.

43. Houve aprovação da Gestão da Saúde pelo Conselho Municipal de Saúde?

44. Qual o percentual de cobertura vacinal para influenza em maiores de 60 anos?

45. Sobre a infraestrutura e necessidade de reparos nas unidades de saúde do município no ano de 2017, responda:

46. Sobre saúde materna e infantil no ano de 2017 , informe:
SIM

NÃO

Quantas unidades de saúde necessitavam de reparos

(conserto de janelas, rachaduras, infiltrações, fiação elétrica, substituição de azulejos danificados, etc) em dezembro de 2017? <Quantidade> ou Não possui registro

Quantas unidades de saúde tiveram seu funcionamento interrompido ou foram abandonadas por problemas de infraestrutura? <Quantidade> ou Não possui registro Número de testes realizados para o diagnóstico da sífilis entre gestantes:

Obs.: Considerar apenas os seguintes procedimentos:

0202031179 VDRL para detecção de sífilis em gestante. 0214010082 teste rápido para sífilis em gestante. 


\begin{tabular}{|c|c|}
\hline & $\begin{array}{l}\text { Número de partos hospitalares do SUS: } \\
\text { Obs.: Considerar apenas os seguintes procedimentos: } \\
\text { - } 0310010039 \text { parto normal. } \\
\text { - } 0310010047 \text { parto normal em gestação de alto risco. } \\
\text { - } \mathbf{0 4 1 1 0 1 0 0 2 6} \text { parto cesariano em gestação de alto risco. } \\
\text { - } \mathbf{0 4 1 1 0 1 0 0 3 4} \text { parto cesariano. } \\
\text { - } \mathbf{0 4 1 1 0 1 0 0 4 2} \text { parto cesariano com laqueadura tubária. }\end{array}$ \\
\hline \multirow{6}{*}{$\begin{array}{l}\text { 47. Quanto aos Centros de Atenção Psicossocial (CAPS) no município, } \\
\text { informe: }\end{array}$} & Número de Caps I: \\
\hline & Número de Caps II: \\
\hline & Número de Caps III: \\
\hline & Número de Caps i: \\
\hline & Número de Caps ad: \\
\hline & Número de Caps ad III: \\
\hline \multicolumn{2}{|l|}{$\begin{array}{l}\text { 48. Qual o número de Equipes de Saúde da Família (ESF) Equivalentes } \\
\text { no município? } \\
\text { Obs.: A equivalência de carga horária do profissional médico para equipe de } \\
\text { Atenção Básica (tradicional) em relação à equipe da Estratégia de Saúde da } \\
\text { Família considera a somatória da carga horária de pediatra, clínico e obstetra } \\
\text { pertencente a uma Unidade Básica tradicional, e a cada } 60 \text { horas há } \\
\text { equivalência para } 1 \mathrm{ESF} \text {. }\end{array}$} \\
\hline \multirow{2}{*}{$\begin{array}{l}\text { 49. As despesas consideradas, para fins de apuração do mínimo constitucional } \\
\text { de aplicação de recursos próprios em saúde, foram de responsabilidade } \\
\text { específica do setor de saúde e com recursos municipais movimentados } \\
\text { somente pelo Fundo Municipal de Saúde? }\end{array}$} & SIM \\
\hline & NÃO \\
\hline \multirow{2}{*}{$\begin{array}{l}\text { 50. Existe controle de tempo de atendimento dos pacientes nas UBS (horário } \\
\text { de entrada } \mathrm{x} \text { horário de atendimento médico)? }\end{array}$} & $\begin{array}{l}\text { SIM } \\
\text { Qual tempo médio de atendimento? }\end{array}$ \\
\hline & NÃO \\
\hline \multicolumn{2}{|l|}{$\begin{array}{l}\text { 51. Qual a soma da carga horária semanal de todos os cirurgiões dentistas das } \\
\text { equipes básicas de saúde bucal do município no ano de 2017? }\end{array}$} \\
\hline \multicolumn{2}{|l|}{$\begin{array}{l}\text { 52. Qual a quantidade de unidades públicas municipais de saúde } \\
\text { (estabelecimentos físicos) existentes no município em 2017? }\end{array}$} \\
\hline $\begin{array}{l}\text { 53. Com base na Lei Complementar } n^{\circ} .141 \text {, de } 13 \text { de janeiro de } 2012 \text {, } \\
\text { informe: }\end{array}$ & $\begin{array}{l}\text { Percentual aplicado em ações e serviços públicos de saúde da } \\
\text { arrecadação dos impostos a que se refere o art. } 156 \text { e dos } \\
\text { recursos de que tratam o art. } 158 \text { e a alínea "b" do inciso I do } \\
\text { caput e o } \int 3^{\circ} \text { do art. } 159 \text {, todos da Constituição Federal: }\end{array}$ \\
\hline $\begin{array}{l}\text { 54. Informe a quantidade de pacientes residentes em outros municípios } \\
\text { atendidos nas UBSs do seu município: }\end{array}$ & $<$ Quantidade $>$ ou Não possui registro \\
\hline \multirow{2}{*}{ 55. Sobre vacinação antirrábica canina no município no ano de 2017, informe: } & Total da população canina no município: \\
\hline & Número total de cães vacinados: \\
\hline $\begin{array}{l}\text { 56. As unidades básicas de saúde possuem equipamentos ou disponibilizam } \\
\text { insumos (fitas, glicosímetros etc.) para medição do nível de glicose dos } \\
\text { pacientes? }\end{array}$ & $\begin{array}{l}\text { SIM, todas as UBS possuem } \\
\text { SIM, a maior parte das UBS possui } \\
\text { SIM, a menor parte das UBS possui } \\
\text { NÃO }\end{array}$ \\
\hline $\begin{array}{l}\text { 57. Os médicos que prestam serviços nas UBS trabalham em regime de } \\
\text { plantão? }\end{array}$ & $\begin{array}{l}\text { Sim - Qual? } \\
\text { Plantão presencial } \\
\text { Plantão de sobreaviso } \\
\text { Não }\end{array}$ \\
\hline
\end{tabular}

\section{Totalização}

Peso da Dimensão Saúde Pública

Pontos máximos: 100

Pontos mínimos: 000

i-SAÚDE: 20/100 - 0,20 (20\%) 